\title{
Stepwise Morphological and Functional Maturation of Mechanotransduction in Rat Outer Hair Cells
}

\author{
Jessica Waguespack, ${ }^{1,2}$ Felipe T. Salles, ${ }^{2}$ Bechara Kachar, ${ }^{2}$ and Anthony J. Ricci ${ }^{1,2,3}$ \\ ${ }^{1}$ Neuroscience Center, Louisiana State Health Sciences Center, New Orleans, Louisiana 70112, ${ }^{2}$ Laboratory of Cellular Biology, National Institute on \\ Deafness and Other Communication Disorders, National Institutes of Health, Bethesda, Maryland 20892, and ${ }^{3}$ Department of Otolaryngology, Stanford \\ University, Stanford, California 94305
}

Inner ear mechanosensory hair cells convert mechanical vibrations into electrical signals via the coordinated interaction of multiple proteins precisely positioned within the sensory hair bundle. Present work identifies the time course for the acquisition and maturation of mechanoelectric transduction (MET) in rat cochlea outer hair cells maintained in organotypic cultures. A spatiotemporal developmental progression was observed morphologically and functionally with basal cochlea maturation preceding apical cochlea by $2-3 \mathrm{~d}$ in all measured properties. The fraction of mechanosensitive cells increased rapidly, with a midpoint at postnatal day 0 for basal cells, and correlated with myosin IIIa immunoreactivity. MET current magnitude increased over several days. Adaptation lagged the onset of transduction by a day and matured more slowly, overlapping but preceding the rise in myosin Ic immunoreactivity. Less than $\sim 25 \%$ of myosin Ic expression was required for the mature adaptation response, suggesting multiple roles for this protein in hair bundle function. Directional sensitivity, lacking in immature responses, developed rapidly and correlated with the pruning of radial links and an increase in tenting of stereociliary tips. Morphological and electrophysiological data support a hypothesis in which key elements arrive independently at the site of MET, with a mature response occurring as membrane tension increases, likely by the increased tensioning of the tip link with the onset of adaptation. Organotypic cultures developed normal, tonotopically specific, MET response properties, suggesting that maturation was not influenced significantly by external factors such as innervation, endolymph, normal mechanical stimulation, or an intact organ of Corti.

Key words: outer hair cells; mechanoelectrical transduction; auditory; adaptation; myosin Ic; myosin IIIa; stereocilium links

\section{Introduction}

The auditory hair cell is a mechanoreceptor, converting deflection of an apically positioned hair bundle into an electrical signal by gating mechanoelectric transduction (MET) channels. These channels are found near the tops of actin-filled stereocilia comprising the sensory organelle (Corey and Hudspeth, 1979; Hudspeth, 1982). MET channels are part of a multiprotein complex that includes the tip link (an extracellular link that may be responsible for translating bundle deflection into force applied to the MET channel), numerous scaffolding proteins, and several myosin isozymes that contribute both to hair bundle formation and to a complex adaptation process (Gillespie and Cyr, 2004).

The traditional model of mechanotransduction postulates the channel to be tethered to the tip link so that the stimulus is directly applied to the channel via protein-protein interactions and

Received May 10, 2007; revised Nov. 2, 2007; accepted Nov. 3, 2007.

This work was supported by National Institute on Deafness and Other Communication Disorders (NIDCD) Grant DC03896 (A.J.R.) and by intramural funding (B.K.). We thank NIDCD for support during evacuation of J.W. and A.J.R. from New Orleans after Katrina. We thank M. Schneider for initial help with culturing organ of Corti and for manuscript review. Myosin Ic antibody was kindly provided by Peter Gillespie.

Correspondence should be addressed to either of the following: Anthony J. Ricci, Department of Otolaryngology, Stanford University, 801 Welch Road, Stanford, CA 94305, E-mail: aricci@stanford.edu; or Bechara Kachar, Laboratory of Cellular Biology, National Institute on Deafness and Other Communication Disorders, National Institutes of Health, Bethesda, MD 20892, E-mail: kacharb@nidcd.nih.gov.

DOI:10.1523/JNEUROSCI.2159-07.2007

Copyright $\odot 2007$ Society for Neuroscience $\quad$ 0270-6474/07/2713890-13\$15.00/0 the channel senses force applied across the membrane (Hudspeth, 1989a; Hudspeth and Gillespie, 1994; Holt et al., 2002). At present there is no direct evidence to support or refute this hypothesis. Although little is known about MET maturation, recent evidence from mouse vestibular hair cells suggests that MET begins before birth between embryonic day 16 (E16) and 17 (Geleoc and Holt, 2003). Embryonic and mature currents were similar in all respects, implicating an "all-or-none" onset to the process that is consistent with the tethering model of MET. The all-or-none hypothesis suggests that the MET complex, including the adaptation components, assembles at the base of the stereocilia and migrates intact to the tops of the stereocilia. In contrast, data from chick basilar papilla (Si et al., 2003) revealed a maturation process in which the size of the MET current increased, adaptation got faster and more complete, and the current-displacement plot shifted rightward, meaning the resting open probability decreased during maturation. This pattern of development indicated that the MET complex assembly undergoes a period of refinement and consolidation.

Development of mechanotransduction was investigated morphologically and electrophysiologically in the rat organotypic culture preparation at two different frequency locations. Data show a spatial and temporal progression of the structural and functional maturation of the hair bundle that is the same between cochlear regions, but for a temporal shift in the onset of the 


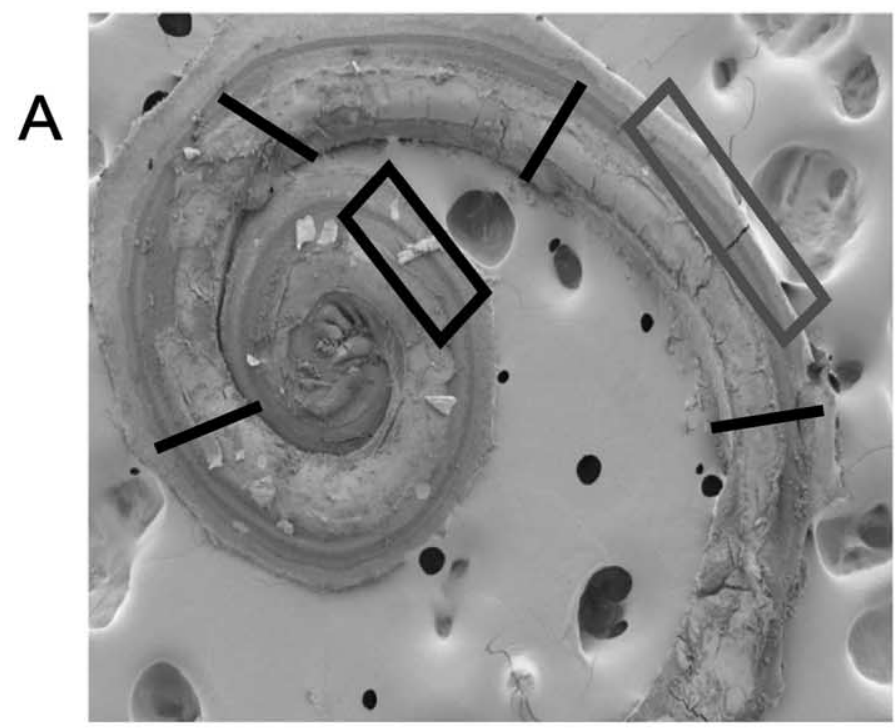

$500 \mu \mathrm{m}$

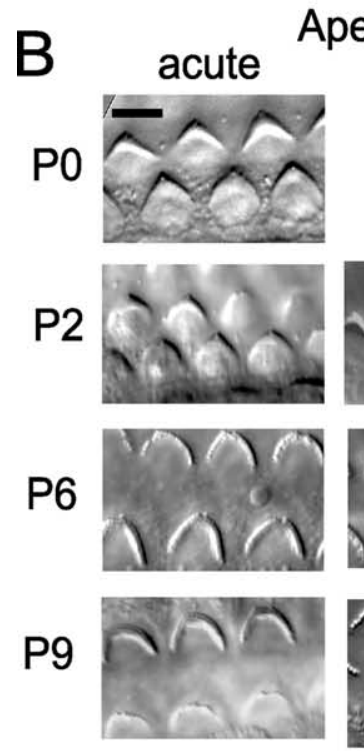

Apex culture
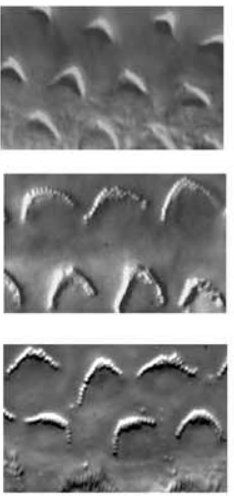
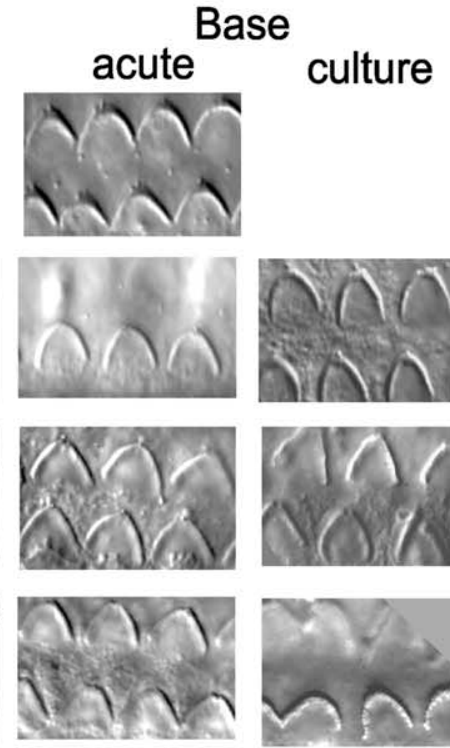
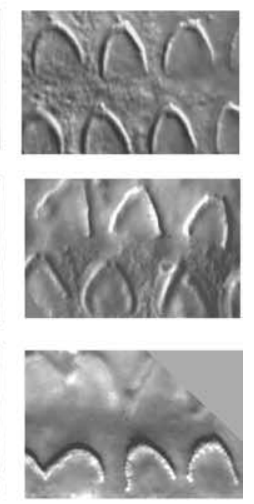

C

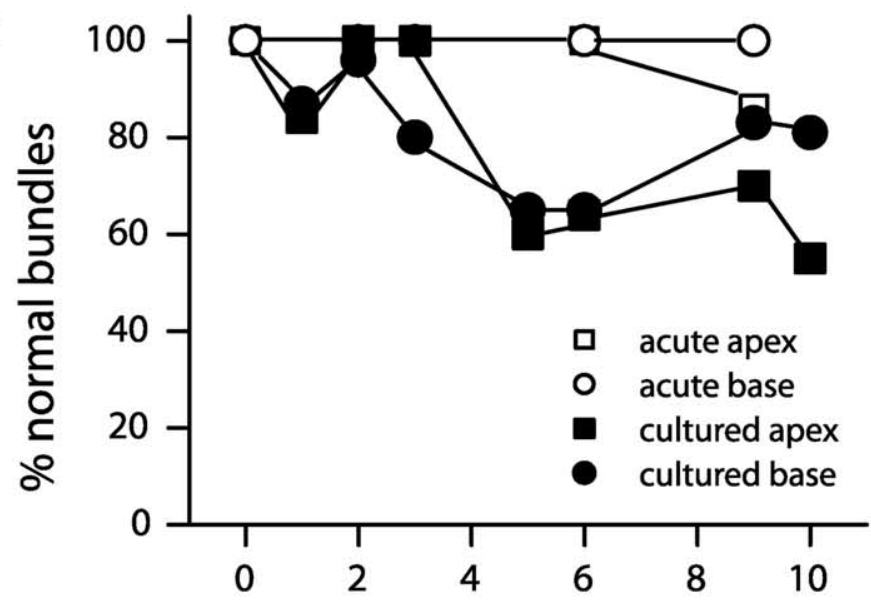

Days after birth process. A novel hypothesis is proposed whereby MET proteins arrive at the site of mechanosensitivity independently, with maturation being driven by progressive tensioning of the stereocilium membrane imposed by the onset and development of adaptation. The stepwise maturation process provides a framework in which to consider alternative mechanisms of activation and maturation.

\section{Materials and Methods}

Tissue preparation and recording. Postnatal day 0 (P0)-P3 Sprague Dawley rat pups (Taconic, Germantown, NY) were decapitated according to National Institutes of Health (NIH) guidelines under the National Institute on Deafness and Other Communication Disorders animal protocol \#1067-02; temporal bones were isolated and placed into L-15 media (Invitrogen, Carlsbad, CA). The organ of Corti was isolated and cut into five pieces (Fig. $1 \mathrm{~A}$ ); each piece was attached to a separate Cell Tak (BD Biosciences, San Jose, CA)-coated coverslip mounted in the bottom of a culture dish (MatTek, Ashland, MA). Cultures were maintained at $37^{\circ} \mathrm{C}$ and $5 \%$ $\mathrm{CO}_{2}$ in DMEM F-12 supplemented with $10 \%$ fetal bovine serum containing $1.5 \mu \mathrm{g} / \mathrm{ml}$ ampicillin (Invitrogen) for at least $2 \mathrm{~h}$ before recording. Cultures were visualized on a Zeiss Axioskop 2 microscope (Thornwood, NY) using Nomarski differential interference contrast optics and a $60 \times$ water-immersion objective [numerical aperture (NA) 0.9, Olympus, Center Valley, PA]. A Cascade 512B digital camera (Photometrics, Tucson, AZ) driven by MetaMorph software (Molecular Devices, Sunnyvale, CA) was used for imaging.

Cells were chosen for electrophysiological investigation based on the hair bundle morphological properties being similar to that of the in vivo hair bundles. Many hair cells developed abnormally shaped hair bundles and were not investigated. Figure 1 compares hair bundles from acutely prepared and cultured organotypic cultures from $\mathrm{P} 0-\mathrm{P} 9$. Both apical and basal bundles matured in culture conditions and were similar to their acutely dissociated

\section{$\leftarrow$}

Figure 1. Cultured hair bundles are morphologically similar to acutely prepared tissue. $A$, Scanning electron micrograph of the cultured organ of Corti. Solid lines represent where the tissue was cut before placement in culture chamber. The boxes represent the regions recorded from electrophysiology (black being apical and gray being basal). $\boldsymbol{B}$, Differential interference contrast images of hair bundles from preparations just before electrical recordings from acutely prepared and organotypic cochlea cultures. Bundles appear morphologically similar at each developmental age. Apical hair bundles mature later than basal bundles. Scale bar, 10 $\mu \mathrm{m}$ for all panels. C, Percentage of hair bundles at each age that appear to have normal morphological features. The organotypic hair bundles deteriorate over time so that by P10, $30-50 \%$ of the hair bundles are abnormally shaped. Recordings were made exclusively from hair bundles with normal appearance. 
partner (Fig. $1 B$ ). The most common difference between culture and acute preparation was a misaligned bundle orientation (Fig. 1) in the cultured preparations. Images of preparations were obtained just before electrophysiological recording. Some culture preparations did not develop normal hair bundles, either having shapes disparate from the in vivo bundles or not developing bundles. The most commonly seen anomalies were bundles with no central region where the kinocilium would be located, and also bundles that had more than three rows of stereocilia and no V-shape appearance. These were not investigated electrophysiologically. Plotting the percentage of hair bundles with normal appearances demonstrates that for the time course used in these investigations, the majority of hair bundles had a normal appearance (Fig. 1C). It should be noted that cultures that were grossly aberrant were not included in these measurements because electrophysiological investigations were not performed. Similarly, acutely dissected preparations in which hair bundles were mechanically damaged were also not included in the morphological assessment because electrophysiological measurements were not made.

To further demonstrate that the culture preparations were developing along a time course similar to in vivo preparations, myosin IIIa labeling was compared between in vitro and in vivo (Fig. $2 A$ ). Myosin IIIa is present in hair cells (Walsh et al., 2002) and was recently shown to label stereociliary tips (Schneider et al., 2006). A similar time course of staining was obtained in vivo and in vitro. In both cases, spatial and temporal gradients were observed in which basal cells expressed myosin IIIa before apical cells and maturation occurred over several days. A second control for the use of the in vitro preparation was to determine whether the final responses were similar between acutely isolated preparations and those grown in vitro, the assumption being that if the end product is the same, then the path to that point is likely comparable. Comparisons of MET between cells obtained by each method revealed no significant difference in measured responses (Fig. 2). Measurements made at P6 for apical cells had peak currents of $536 \pm 176 \mathrm{pA}(n=6)$ and $377 \pm 223 \mathrm{pA}(n=5)$ for acutely prepared and organotypic cultures, respectively. Fast adaptation time constants, measured from stimulations that elicit $<50 \%$ of the maximal current, were also not statistically different, having values of $0.6 \pm 0.3 \mathrm{~ms}$ and $0.6 \pm 0.3 \mathrm{~ms}$ for acute and cultured preparations, respectively. Finally, current-displacement plots showed no difference in slope or half-activation values (Fig. 2C). Data were fit with the equation for a double Boltzmann function as follows:

$$
\begin{gathered}
I / I_{\text {max }}=\left\{1+\left(1+\exp \left(a_{1} \times x_{0}-a_{1} \times x\right)\right.\right. \\
\left.\left.\times\left(1+\exp \left(a_{2} \times x_{0}-a_{2} \times x\right)\right)\right)\right\}^{-1},
\end{gathered}
$$

where $a_{1}$ was $3.8 \pm 0.6$ and $4.4 \pm 1.3, x_{0}$ was $0.69 \pm 0.13$ and $0.60 \pm 0.2 \mu \mathrm{m}$, and $a_{2}$ was $1.9 \pm 0.8$ and $3.5 \pm 1.3 \mu \mathrm{m}^{-1}$ for acute versus cultured samples.
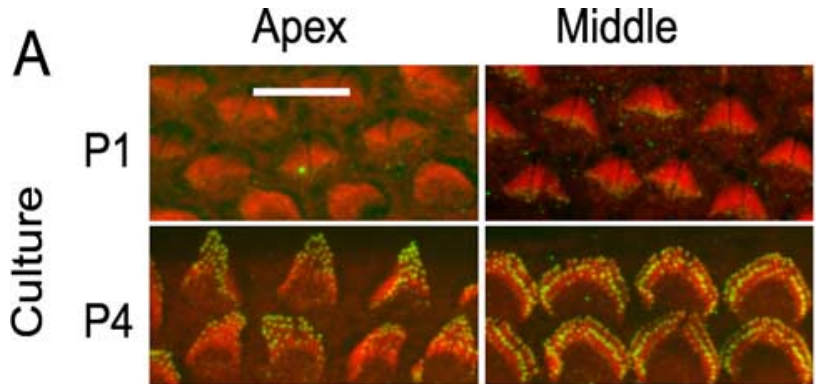

Base
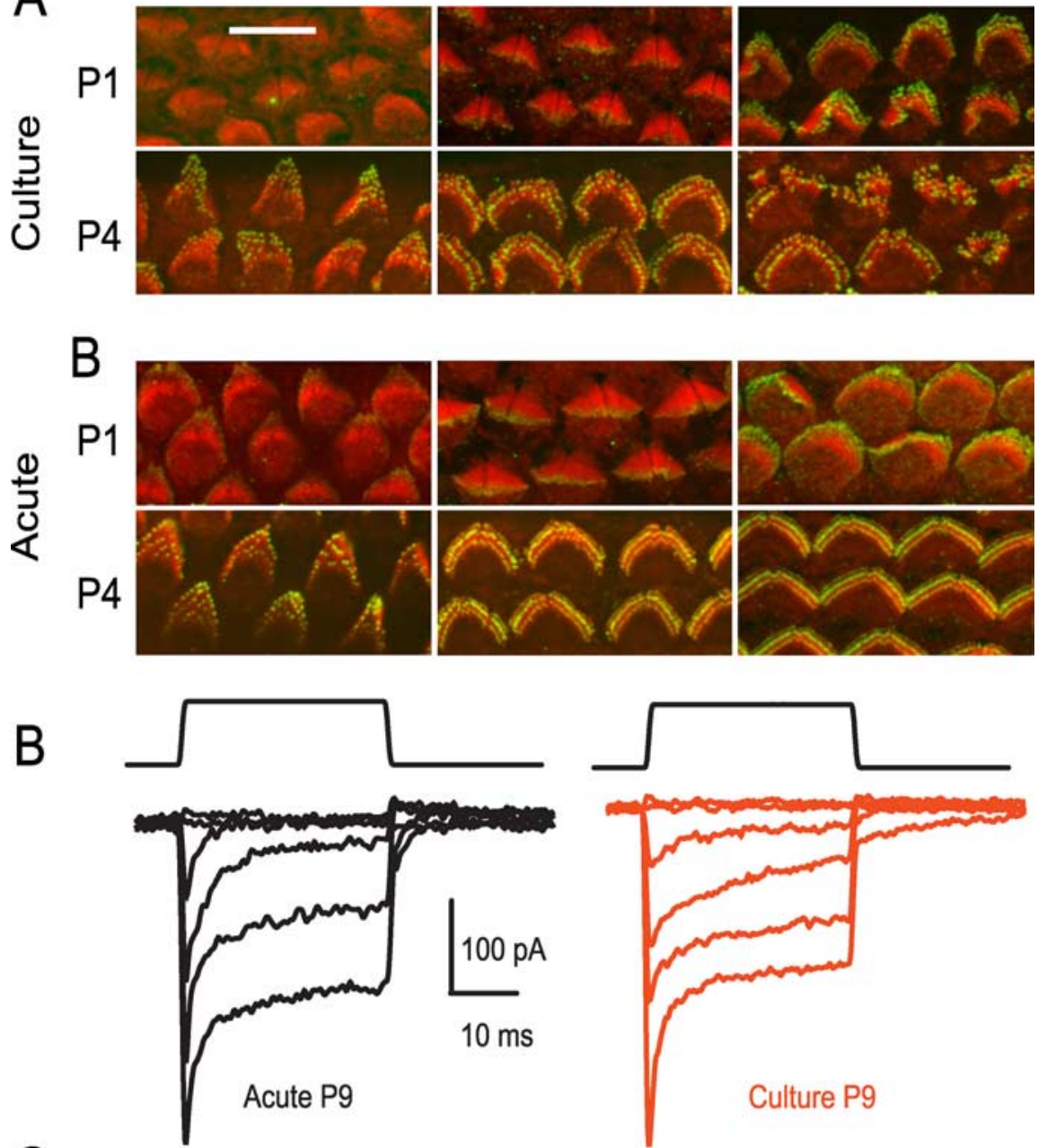

C

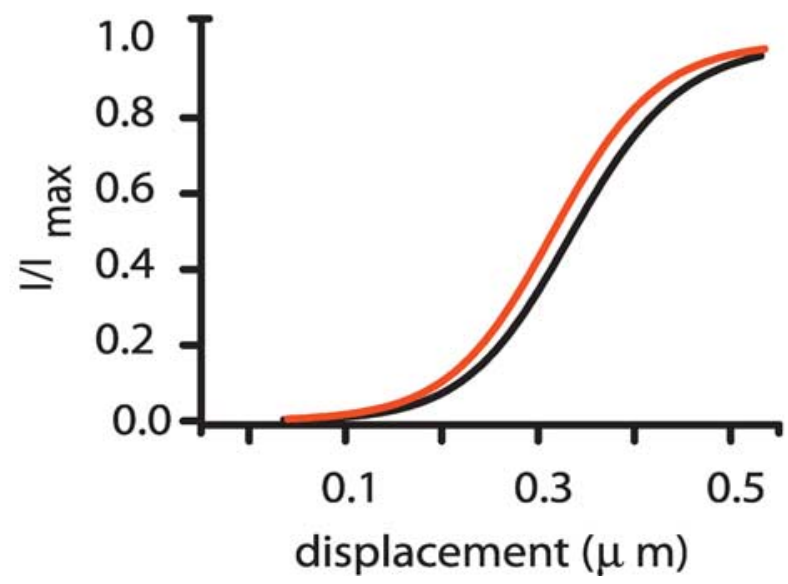

Figure 2. $A$, Myosin Illa localizes to the stereocilia in both culture and acute preparations. Both spatial and temporal progression of myosin Illa staining were similar in vivo and in vitro. Myosin Illa (green) appears in basal hair bundles before it appears in apical hair bundles both in cultured (top) and acute (bottom) preparations. At P1, myosin Illa was observed in basally located bundles, only slightly in bundles from midregions, and not in apical hair bundles, a pattern matched in the acute preparations. Red staining is actin labeled with phalloidin. Scale bar, $10 \mu \mathrm{m}$ for all panels. Misformed hair bundles also show the myosin Illa localization as depicted in the basal hair cells in P4 organotypic cultures. $\boldsymbol{B}$, Mechanically elicited currents from apical hair cells at P6 or $6 \mathrm{~d}$ in culture. Cells were voltage clamped at $-80 \mathrm{mV}$ and mechanically stimulated between -100 and $1000 \mathrm{~nm}$ (a single stimulus trace is shown above currents for timing). No differences were observed in activation, adaptation, or current amplitudes between acute and cultured cells (see text for details). C, Averaged activation curve for acute $(n=6)$ and cultured $(n=5)$ mechanically activated currents. These curves were not statistically different (see text for details). 


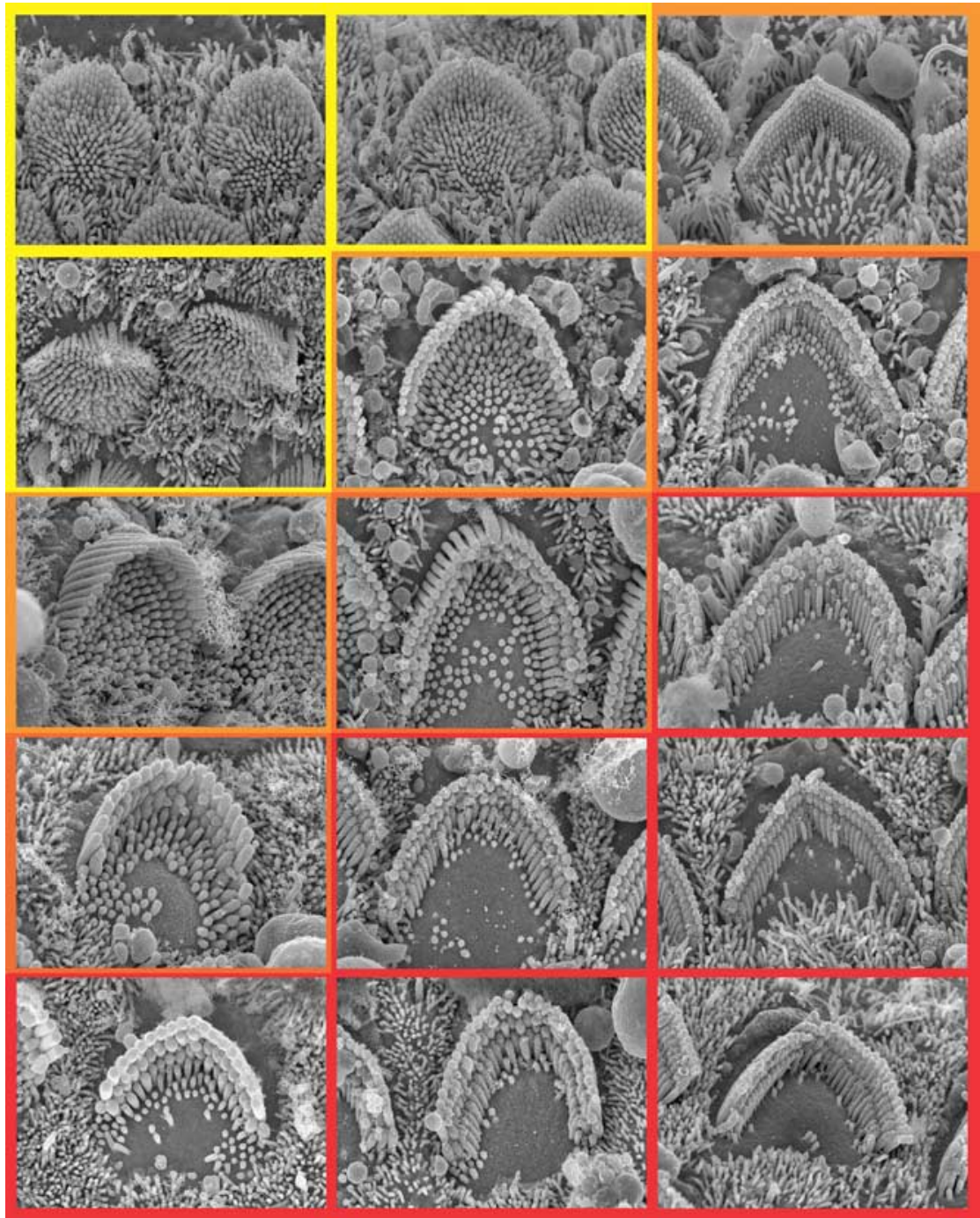

Figure 3. Morphological maturation of rat $\mathrm{OHC}$ hair bundles. Scanning electron micrographs of developing $\mathrm{OHC}$ bundles from three positions along the cochlea at ages ranging from P1 to P9. The border color reflects the onset of mechanosensitivity. Yellow means no response, and red means mature response. Both temporal and spatial gradients were observed in the shape of the hair bundles, height of the stereocilia, and number of stereocilia. Scale bar, $4 \mu \mathrm{m}$ for all panels.

The in vitro preparation provided a more convenient means to investigate MET properties because it lacked the variability created by mechanical damage during tissue preparation, particularly at young ages when not all cells were responding and the amplitudes of MET responses were quite variable. Also, the cultured preparation survived longer under recording conditions than did the acutely prepared preparation, again likely a result of the mechanical load to the hair cells during tissue preparation.

The basolateral surfaces of the outer hair cells (OHCs) were accessed by bringing a patch pipette filled with L-15 media (Invitrogen) parallel to the rows of cells and making a hole using back pressure onto the pipette to clear a path to the cells. Separate recording pipettes were then advanced through the hole to the basolateral surface of the OHCs. The cells were whole-cell voltage clamped at room temperature in L-15 media using borosilicate patch electrodes (1.2 mm outer diameter; WPI, Sarasota, Fl) connected to an Axopatch 200 amplifier (Molecular Devices) at $-80 \mathrm{mV}$. The patch electrodes were filled with an internal solution containing (in $\mathrm{mM}$ ) $145 \mathrm{KCl}, 3.5 \mathrm{MgCl}_{2}, 5 \mathrm{ATP}, 5$ creatine phosphate, 1 EGTA, 10 HEPES, and 2 ascorbate, $\mathrm{pH}$ 7.4. Data were digitized with a CED (Cambridge Electronic Devices, Cambridge, UK) under the control of JClamp software. Each stimulus protocol was obtained as an average of four stimuli. Hair bundles were mechanically deflected with a glass pipette attached to a piezoelectric stack actuator (Piezosystem Jena, Hope- dale, MA). Stimuli were generated with the CED DA converter and JClamp software (SciSoft, Yale University, New Haven, CT) and were filtered at $2-5 \mathrm{kHz}$ to limit resonance of the piezo stack (Ricci et al., 2005). The stimulus range was chosen to encompass the operating range of the hair bundle at its particular stage of development. The piezo could generate steps of several micrometers. The tip of the pipette was fire-polished so that it fit into the V-shaped stereociliary bundle of the outer hair cell. The glass probe was cleaned in chromic acid to help it adhere to the bundle. Care was taken to ensure that even when the bundles were short, the probe did not stimulate the apical surface, which might inadvertently slow the stimulus and result in artificial responses. Measurements were repeated with the probe at higher positions to ensure accurate measurements. The elevated probe position required that the stereocilia be connected to receive stimulation in that the shorter stereocilia were not directly accessed by the probe.

Antibodies. Affinity-purified myosin IIIa polyclonal antibody was raised against a peptide sequence of the $C$ terminus (NPYDYRRLLRKTSQRQR) of mouse as previously described (Schneider et al., 2006). Affinity-purified polyclonal anti-myosin Ic antibody (Dumont et al., 2002) was graciously provided by Peter Gillespie (Vollum Institute, Portland, OR).

Immunofluorescence. Immunofluorescence localization of myosins was performed either on whole-mount preparations of acute or cultured organ of Corti obtained from rat. Animals were killed by rapid decapitation if younger than P10 or anesthetized with $\mathrm{CO}_{2}$ before decapitation if older, in accordance with $\mathrm{NIH}$ guidelines. Tissues were fixed with $4 \%$ PFA in $\mathrm{PBS}$, at $25^{\circ} \mathrm{C}$ for $2 \mathrm{~h}$. Acute preparations were dissected in PBS. Samples were permeabilized with $0.5 \%$ Triton X-100 (Sigma) in PBS and blocked overnight at $4^{\circ} \mathrm{C}$ in $2 \%$ bovine serum albumin (Sigma) in PBS. Organ of Corti pieces were incubated with primary antibody (myosin IIIa or myosin Ic) for $2 \mathrm{~h}$ and then washed three times in PBS before staining with Alexa Fluorconjugated secondary antibody (Invitrogen) for $1 \mathrm{~h}$. Pieces were washed, counterstained with Alexa Fluor 568 phalloidin, washed with PBS, and mounted between slide and coverslip using Prolong anti-fade (Invitrogen).

Fluorescence images were obtained with a Nikon microscope using 60 or $100 \times 1.4 \mathrm{NA}$ objectives and a spinning disk confocal unit (PerkinElmer, Waltham, MA). Fluorescence was quantified using NIH Image, by measuring the difference in average pixel intensity between a region over the hair bundle and an arbitrary neighboring background region.

Scanning electron microscopy. Both cultured and freshly dissected cochleae were processed for scanning electron microscopy either by OTOTO (osmium-thiocarbohydrazide-osmium-thiocarbohydrazideosmium) (Friedman and Ellisman, 1981) or by sputter coating and viewed on a Hitachi S-4800 (Hitachi, Pleasanton, CA), operated at $5 \mathrm{kV}$

Analysis. Analysis was performed using JClamp and Origin (Microcal Software, Northampton, MA). Adaptation time constants were measured by fitting a second-order exponential to the current decay in response to a stimulus that elicited less than one-half the maximal transducer current. The equation used was as follows:

$$
I=I_{0}+A_{1} e^{-t / t_{1}}+A_{2} e^{-t / t_{2}} .
$$



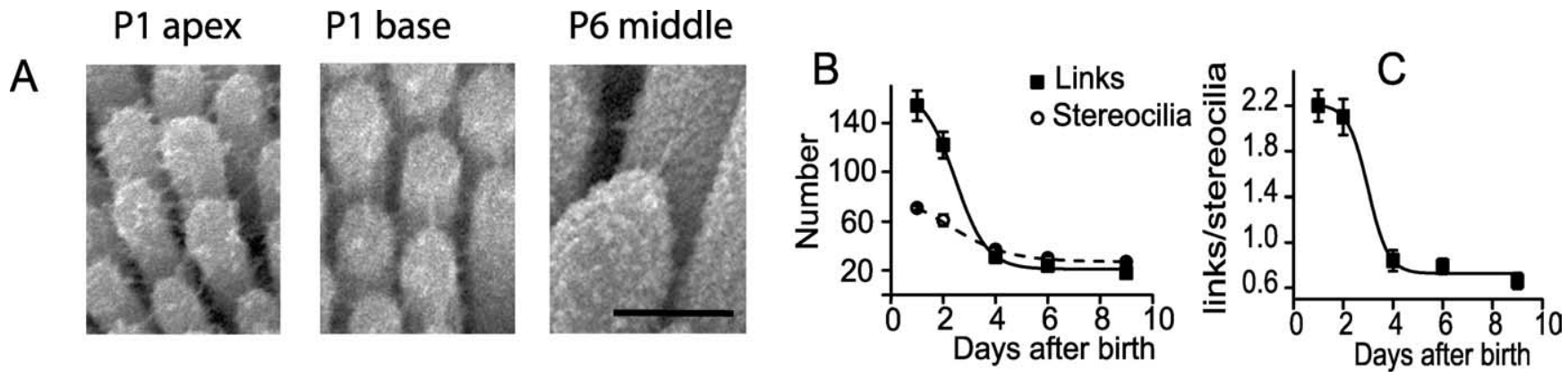

Figure 4. Hair bundles undergo pruning of both stereocilia and interstereociliary links. A, Higher-magnification electron micrographs of an immature (left), middle-aged, and mature hair bundle (right) depicting the change in stereocilium number, size, and interciliary connections. Scale bar, $0.35 \mu \mathrm{m}$ for all panels. B, Quantification of the number of stereocilia and interciliary links counted in a uniform midregion of apical hair bundles from P0 through P9 ( $n=10$ for each data point). Larger hair bundle regions than shown in $A$ were used for these measurements (see text). Sigmoidal functions were fit to the data with a resulting slope of $1.6 \pm 0.5$ for the pruning of stereocilia and $0.6 \pm 0.4$ number $/ \mathrm{d}$ for the pruning of interciliary links. The midpoint of these plots was $2.5 \pm 0.3 \mathrm{~d}$ for stereocilium number and $2.2 \pm 1.2 \mathrm{~d}$ for interciliary links. Correlation coefficients were 0.99 and 0.98 for stereocilia and links, respectively. C, The ratio of links to stereocilia demonstrates that the links are pruned at a more rapid rate, although over a similar time course, than stereocilia. This plot was also fit with a sigmoidal function having a slope of $0.4 \pm 0.6$ (links/stereocilium)/d and a midpoint of $3 \pm 2 \mathrm{~d}\left(r^{2}=0.99\right)$.

The current-displacement plot was normalized to the maximum current and fit to a sigmoidal equation of the following form:

$$
y=1 /\left(1+e^{\left(\left(x-x_{0}\right) / d x\right)}\right),
$$

where $x_{0}$ equals the half-activation and $\mathrm{d} x$ equals the steepness. Data are presented as mean \pm SEM. This equation was used rather than the double Boltzmann (Eq. 1) to separate slope and half-activation more easily.

Either single-exponential or sigmoidal functions were used to fit the maturation process depending on how the data presented; no specific mechanism is implied. Equation 3 was used whenever a sigmoidal function could be applied, and the units varied based on the particular plots, in some cases age and in others displacement.

Student's unpaired $t$ test was used to determine statistical significance at the $p<0.01$ level between apical and basal measurements. All fits used a least-squares method, and correlation coefficients $\left(r^{2}\right)$ are given with each fit.

\section{Results}

The development of the mouse cochlea follows a temporal gradient initiated by a wave of differentiation beginning in the base at E14.5 and spreading to the apex by E17.5 (Lee et al., 2006). Hair cell markers myosin VIIa and myosin IIIa and bundle morphology subsequently follow a similar pattern (in rat) (Zine and Romand, 1996; Chen and Segil, 1999; Schneider et al., 2006). Although it is hypothesized that the onset of mechanotransduction follows a similar pattern, little is known about the assembly of the MET apparatus and the maturation of the MET response in the mammalian cochlea or organotypic culture. The relationship between mechanosensitivity and hair bundle structure is uncharacterized. The spatial and temporal maturation of the hair bundle structure and function were thus characterized in the organotypic rat culture.

\section{Morphological maturation}

Hair bundles appear at E20 and undergo significant morphological changes over the next week (Zine and Romand, 1996). Scanning electron micrographs of hair bundles from the apical, middle, and basal turns of cochleas from P1-P9 rat pups were examined (Fig. 3). Morphological changes progressed both spatially and temporally with basal hair bundles maturing $\sim 2 \mathrm{~d}$ earlier than apical bundles. The most immature hair bundles had multiple rows of thin stereocilia that showed comparable heights between rows (Fig. 3, P1 and P2 apical). Maturation involved stereocilia thickening, elongation, and organization into a staircase pattern of increasing height. Simultaneously, the number of rows of stereocilia was reduced. A similar maturation progression was observed at each location with basal maturation preceding that in the apex by $\sim 2 \mathrm{~d}$. These developmental morphological changes are similar to those observed in hamster (Kaltenbach et al., 1994).

Along with the macroscopic changes in hair bundle height and shape, interciliary connections also underwent significant changes. The immature bundle had many interciliary connections radiating in all directions from the stereocilia (Fig. 4A). As maturation progressed, pruning of radial links continued while maintaining connections in what would be the final directionally sensitive polarity. The final panel shows a more mature stereocilium as is clear from the single tip link connection along the directionally sensitive axis, the larger stereocilia diameter and tenting (stretched, conical appearance of the shorter stereocilia) of the tip compared with the less mature stereocilia, suggesting an increased tension of the membrane by the tip link (Prost et al., 2007).

In an attempt to quantify the observed pruning of interciliary links, electron micrographs of hair bundles were taken at five time points from apical hair bundles ( $n=10$ at each point). Supplemental Figure 1 (available at www.jneurosci.org as supplemental material) shows each of the bundle regions chosen for each time point presented. An arbitrary region of uniform size in the middle of the hair bundle was used, where the orientation was similar between sections. The number of stereocilia were counted in each region, as were the number of visible links (no attempt was made to differentiate between link type). Figure $4 B$ plots the number of stereocilia (open circles) and the number of links (filled squares). Data were fit with the sigmoidal function (Eq. 3). The slopes measured were $1.6 \pm 0.5\left(r^{2}=0.99\right)$ cilia/d for stereocilium pruning and $0.61 \pm 0.4\left(r^{2}=0.98\right)$ links/d for link pruning with midpoints of $2.5 \pm 0.3 \mathrm{~d}$ for stereocilia and $2.2 \pm 1.2 \mathrm{~d}$ for interciliary links. The change in links was not simply a function of a loss of stereocilia, as is demonstrated by the plot of the ratio of links per stereocilium versus days after birth (Fig. 4C). A sigmoidal function to this plot has a midpoint of $3 \pm 2 \mathrm{~d}$ and a slope of $0.4 \pm 0.6$ links per cilia per day, indicating that links are pruned more than twice as fast as stereocilia. These results are also similar to those described in hamster (Kaltenbach et al., 1994).

\section{The onset of mechanosensitivity}

Mechanosensitivity matured over a time course similar to that of hair bundle development. OHC responses to hair bundle deflec- 

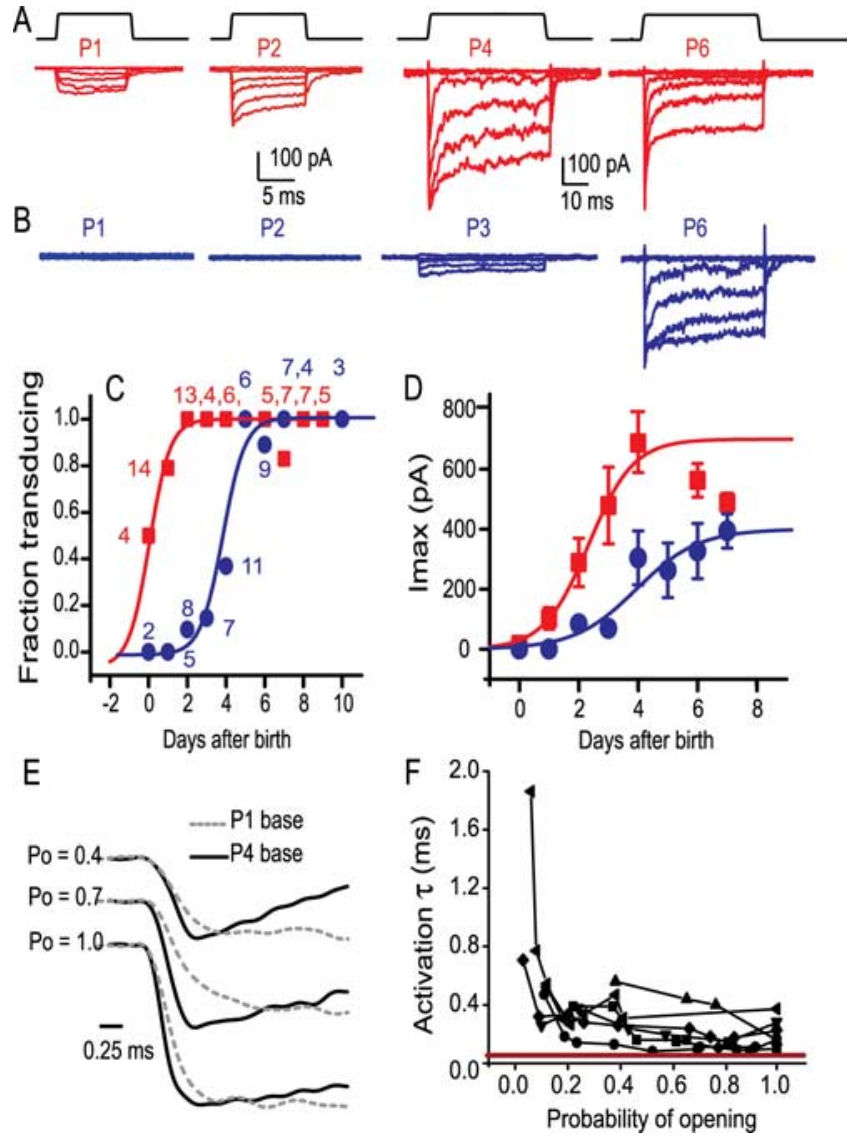

Figure 5. The onset of transduction occurs with a temporal and spatial gradient from base to apex in rat cochlea cultures. $\boldsymbol{A}, \boldsymbol{B}$, Transduction responses from hair cells voltage clamped at $-80 \mathrm{mV}$ from ages P1, P2, P4, and P6 basal $(\boldsymbol{A})$ and P1, P2, P3, and P6 for apical hair cells $(\boldsymbol{B})$. The time course of the stimulus is shown above the current records. The stimulus amplitudes varied to encompass the entire activation range for a given cell; for the basal P1, stimuli were $-221,508,766,1515$, and $1631 \mathrm{~nm}$; for P2, $-157,162,320,478$, and $803 \mathrm{~nm}$; for P4, -220 , $262,482,728$, and $987 \mathrm{~nm}$; for $\mathrm{P6},-90,150,290,350$, and $400 \mathrm{~nm}$; for apical recordings at $\mathrm{P1}$ and P2, stimuli were $-221,508,1515,1631 \mathrm{~nm}$; for P3, $-310,136,420,694$, and $1114 \mathrm{~nm}$; and for P6, $-265,286,450,603$, and $916 \mathrm{~nm}$. C, Time course of the onset of transduction for apical (blue) and basal (red) outer hair cells ( $n$ is indicated by each point). The proportion of recorded cells in which transduction was present is plotted against days after birth. Data were fit with sigmoidal functions with slopes of $0.53 \pm 0.11$ and $0.53 \pm 0.17 \mathrm{~d}^{-1}$ and midpoints of $0.04 \pm 0.17$ and $3.9 \pm 0.2 \mathrm{~d}$ for basal and apical cells, respectively $\left(r^{2}\right.$ for fits were 0.96 and 0.98 for base and apex). D, The increase in MET current amplitudes during maturation. Here, too, data were fit with sigmoidal functions. $I_{\max }$ was fixed at $400 \mathrm{pA}$ and $700 \mathrm{pA}$ for apical and basal cells, respectively. Slope values were $0.83 \pm 0.06\left(r^{2}=0.9\right)$ for basal and $1.02 \pm 0.33 \mathrm{pA} / \mathrm{d}\left(r^{2}\right.$ $=0.76$ ) for apical hair cells. Midpoint values were $2.4 \pm 0.1$ and $3.5 \pm 0.4 \mathrm{~d}$ for basal and apical cells, respectively. $\boldsymbol{E}$, Activation kinetics were slower in immature responses than in mature responses. Data were normalized to maximal current and to relative probability of opening. $\boldsymbol{F}$, Activation kinetics for P1 basal cell recordings. Activation was slower than the stimulus rise time (shown by red line) for each cell. More mature responses activated with kinetics that matched the stimulus rise time.

tion were measured beginning at postnatal day 0 from both basal and apical locations (Fig. 5). MET currents were detected in 50\% of $\mathrm{P} 0$ basal OHCs, with an average peak amplitude of $16 \pm 5 \mathrm{pA}$ (Fig. 5) (holding potential of $-80 \mathrm{mV}$ ). The current amplitude and percentage of responsive cells increased over time until peaking at $687 \pm 98 \mathrm{pA}$ at $\mathrm{P} 4$ for basal cells, when $100 \%$ of the cells were mechanosensitive (Fig. $5 C$ ). In contrast, mechanosensitivity did not appear in apical OHCs until P2, reaching maturity around P6, with an average peak current of $394 \pm 57$ pA (Fig. $5 D)$. The apical cells were more "all-or-none" than the basal cells, so that few cells were obtained that had the smaller currents ob- served in the basal cells. Recordings before P4 had only two mechanosensitive cells, and at P4 the currents were larger, with most showing some level of adaptation. The sigmoidal fits to the data in Figure $5 C$ had the same slopes of $0.5 \pm 0.1$ and $0.5 \pm 0.2$ $\mathrm{d}^{-1}$ with midpoints of $0.04 \pm 0.17$ and $3.9 \pm 0.2 \mathrm{~d}$ for basal and apical cells, respectively. The tonotopic delay in transduction onset was similar to that for hair bundle morphological maturation (Zine and Romand, 1996) (Figs. 2-4). The color scheme presented in Figure 3 superimposes the time course of onset of mechanosensitivity with hair bundle morphological maturation to demonstrate a correlation. The change in peak current also followed a sigmoidal shape in which the slope values were not different at $0.83 \pm 0.06$ and $1.0 \pm 0.3 \mathrm{nA} / \mathrm{d}$ for basal and apical cells; however, the midpoints were different at $2.4 \pm 0.1$ and $3.5 \pm 0.4 \mathrm{~d}$ (Fig. 5D). No difference was found between peak currents obtained for the mature hair cells in culture compared with acutely isolated preparations (Fig. 2) $(p>0.05)$. Currents obtained in both instances were smaller than those reported in other rat preparations or in gerbil (Kennedy et al., 2003; He et al., 2004), likely because of technical differences in stimulation.

\section{Maturation of activation kinetics}

Immature MET currents differed from mature responses by activating slowly. Normalizing the currents to their maximal response allowed comparisons of activation kinetics at different stimulus levels. To normalize the difference in the set point of the current-displacement plots (see Fig. 7), data were compared based on probability of opening $\left(P_{\mathrm{o}}\right)$ (Fig. $5 E$ ). Immature responses (P1) activated considerably slower at each stimulus level compared with the more mature (P4) response (Fig. $5 E, F)$. It is possible that the onset of adaptation decreased the time to peak, ostensibly by clipping the peak response earlier as adaptation got faster. Simulations to test this possibility suggest that the adaptation rates at these time periods are too slow to change activation kinetics enough to account for the measured responses. Plotting the activation time constant against open probability for five P1 basal recordings demonstrates that in each case the kinetics are slower than the stimulus rise time (Fig. $5 F$, red line). Later recordings typically showed kinetics similar to the stimulus rise time. The activation kinetics were quite variable, and often the rise time would have multiple components. This variability lessened during maturation as the kinetics became faster than the stimulus rise time. The change in activation kinetics is predicted to be a reflection of a more accurate translation of hair bundle deflection to force sensed by the channel, likely provided by better coupling between the membrane and cytoskeletal core.

\section{Development of adaptation}

MET currents at the onset of mechanosensitivity showed no or little temporal adaptation (Figs. 5A, 6A). Adaptation progressively became faster and more complete over the several days after the onset of mechanosensitivity (Figs. 5, 6). The onset of adaptation could be fit with a sigmoidal function that had slopes of $0.33 \pm 0.13$ and $0.30 \pm 0.03 \mathrm{~d}^{-1}$ and midpoints of $1.3 \pm 0.2$ and $4.70 \pm 0.04 \mathrm{~d}$ for basal and apical cells, respectively. All basal cells showed adaptation by day 3 , apical cells by day 6 , a delay compared with the onset of mechanosensitivity of approximately $1 \mathrm{~d}$ (compare Fig. $6 B$ to Fig. $5 B$ ).

Fast adaptation, whose mechanism remains controversial, is considered to play a significant role in mechanically tuning the hair bundle (Ricci, 2003; Ricci et al., 2005). The time constant of fast adaptation varies tonotopically in the mature OHC (Ricci et al., 2005). During maturation, the fast adaptation time constants 
decreased from $1.2 \pm 0.3 \mathrm{~ms}$ on P1 to $0.18 \pm 0.05 \mathrm{~ms}$ on $\mathrm{P} 6$ in basal OHCs, whereas in apical OHCs, the adaptation time constants decreased from $1.2 \pm 0.2 \mathrm{~ms}$ on $\mathrm{P} 4$ to $0.4 \pm 0.1 \mathrm{~ms}$ on P7. Although there was no difference between initial time constants between apical and basal cells, the difference in time constants in mature cells was statistically significant (two-tailed $t$ test, $p<$ 0.005). Thus tonotopic differences developed in culture despite the nonphysiological environment and the fact that apical and basal tissues were grown separately.

The development of adaptation lagged the onset of mechanosensitivity by approximately $1 \mathrm{~d}$ (Fig. $6 B$ ). The percentage of basal OHCs that showed adaptation increased from 0 at birth to $86 \pm$ $6 \%$ at P4 (Fig. 6 B). For apical cells a similar range was observed, but maturation was not complete until P8. These data could be fit with sigmoidal functions with slopes of $0.3 \pm 0.1$ and $0.5 \pm 0.1$ $\mathrm{d}^{-1}$ and midpoints of $1.3 \pm 0.2$ and $4.5 \pm 0.2 \mathrm{~d}$ for basal and apical cells, respectively. Again the difference was not in the shape of the curve but in the position along the time axis.

The time course of maturation for the adaptation time constant was fit with a single-exponential equation revealing time constants not significantly different at $1.2 \pm 0.2$ and $1.4 \pm 0.5 \mathrm{~d}$ (Fig. 6C). Curves were shifted in time by $3 \mathrm{~d}$ with basal maturation preceding apical. The steady-state values from the exponential fit, an indicator of mature adaptation rate, were $0.18 \pm 0.01$ and $0.35 \pm 0.06 \mathrm{~ms}$ for basal and apical cells, respectively, supporting the conclusion that tonotopic differences were maintained in the developing culture.

Slow adaptation or motor adaptation has been linked to a myosin-based mechanism (Eatock et al., 1987; Holt et al., 2002; Gillespie and Cyr, 2004). The time constant of slow adaptation is quite variable, ranging from the tens to hundreds of milliseconds (Eatock et al., 1987; Hudspeth, 1989b; Gillespie and Cyr, 2004). No tonotopic variation in slow adaptation has been reported nor has slow adaptation been directly investigated in mammalian auditory hair cells. By fitting double exponentials to slightly larger stimuli $\left(P_{\mathrm{o}}>0.5\right)$, the slow time constant of adaptation was obtained (Fig. 6D). The slow time constant decreased with maturation from tens of milliseconds to single milliseconds, the fastest reported slow component to date (Fig. 6 F). Fitting the maturation process with sigmoidal functions yielded a response time of $2.4 \pm 0.5$ and $2.6 \pm 0.8 \mathrm{~ms}$ for basal and apical cells, respectively. No tonotopic difference was found in the mature response. Slopes of $0.8 \pm 0.8$ and $1.1 \pm 0.5 \mathrm{~d}^{-1}$ were not different, whereas midpoints of $4 \pm 1$ and $8 \pm 1 \mathrm{~d}$ were different between basal and apical cells, respectively $(p<0.01)$. The slow time constant matured more slowly than did the fast time constant. The stimulus durations used preclude investigation of existence of longer time constants.

The extent of adaptation can be approximated by taking the ratio of peak current to steady state (Wu et al., 1999). The extent of adaptation increased during maturation (Fig. 6E). Sigmoidal fits to these data yielded slopes that were not significantly different at $0.3 \pm 0.1$ and $0.5 \pm 0.1 \mathrm{~d}^{-1}$ and midpoints of $1.3 \pm 0.2$ and $4.5 \pm 0.2 \mathrm{~d}$ for basal and apical cells, respectively. The maturation of the extent of adaptation requires both fast and slow components of adaptation.

\section{The MET activation curve shifts over time}

The maturation of adaptation paralleled a shift in the currentdisplacement $(I-x)$ plot for MET activation. A leftward shift occurred (Fig. 7A) that was quite large, correlating with a decrease in half-activation from $0.7 \pm 0.1 \mu \mathrm{m}$ at $\mathrm{P} 1$ to $0.3 \pm 0.1 \mu \mathrm{m}$ at $\mathrm{P} 6$ for basal OHCs. The apical OHCs showed similar shifts, but mat-
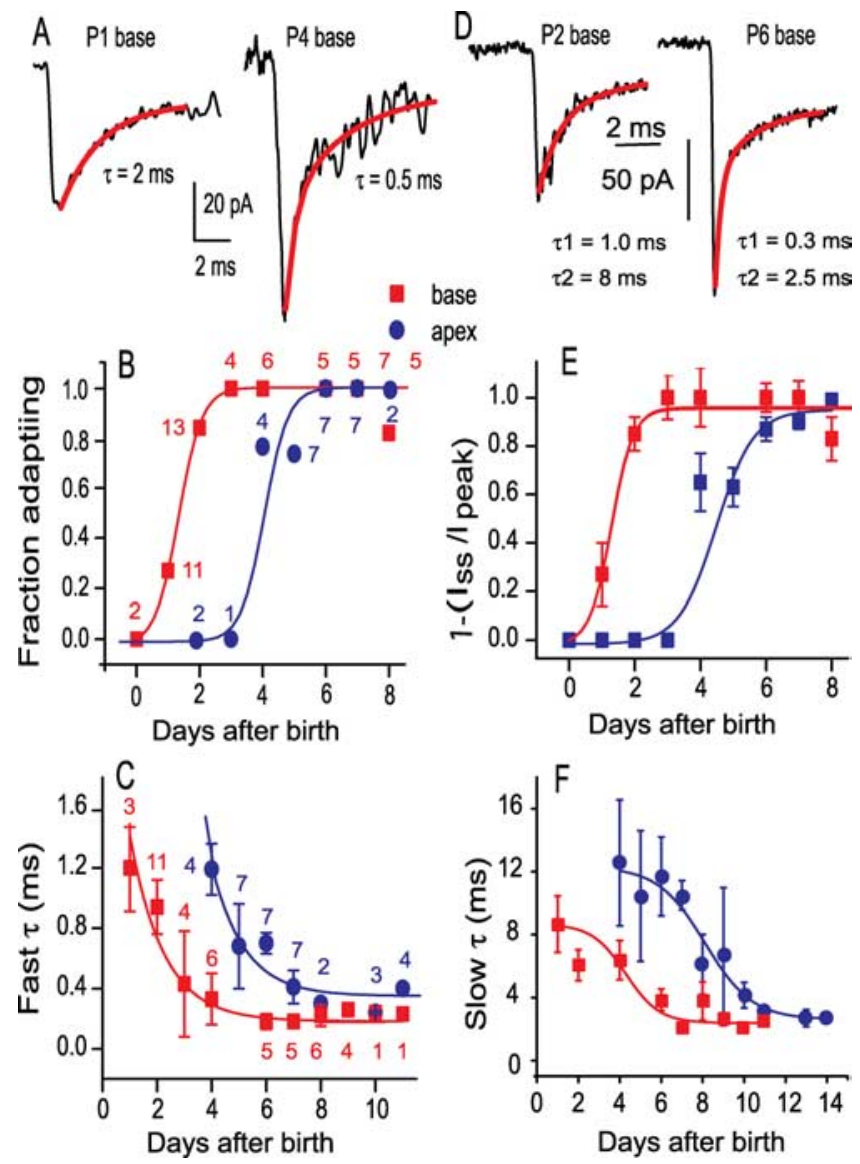

Figure 6. The onset of adaptation is delayed compared with the onset of transduction. Adaptation matures over a short time period, first appearing slow and incomplete and then maturing to its final rate. $\boldsymbol{A}$, Examples of MET currents from basal cells at P1 and P4 voltage clamped at $-80 \mathrm{mV}$ in response to 300 and $110 \mathrm{~nm}$ stimuli, respectively. Time constants were measured as fits to a simple double-exponential equation, fits shown in red. $\boldsymbol{B}$, The proportion of transducing cells with adapting responses is plotted against days after birth ( $n$ is given near each data point). Data were fit with sigmoidal functions in which the slopes were $0.33 \pm 0.13$ $\mathrm{d}^{-1}$ and $0.32 \pm 0.16 \mathrm{~d}^{-1}$ and the midpoints were $1.3 \pm 0.2$ and $3.9 \pm 0.1 \mathrm{~d}$ for basal $\left(r^{2}=\right.$ $0.95)$ and apical cells $\left(r^{2}=0.99\right)$, respectively. A plot of the fast adaptation time constant against days in culture $(\boldsymbol{C})$ demonstrates the development of a tonotopic distribution. Data were fit with exponential curves in which the baseline value represents the mature response and was respectively $0.18 \pm 0.01\left(r^{2}=0.9\right)$ and $0.35 \pm 0.06 \mathrm{~ms}\left(r^{2}=0.89\right)$ for basal and apical cells, demonstrating that tonotopy develops in the cultured preparation. The time constant for maturation was $1.2 \pm 0.2$ and $1.4 \pm 0.5 \mathrm{~d}^{-1}$ for basal and apical cells, respectively. $\boldsymbol{D}$, Examples of maturation of the slow time constant for a $\mathrm{P} 2$ and $\mathrm{P} 6$ basal cell in response to steps that elicit $\sim 50 \%$ of the maximal current. Double-exponential fits to the current decay are shown in red. $\boldsymbol{E}$, The extent of adaptation, measured as 1 - (steady-state current)/(peak current), increased during development over a similar time course as the adaptation time constant quickens for both apical and basal cells. Sigmoidal fits to these data yielded slopes that were not significantly different at $0.3 \pm 0.1$ and $0.5 \pm 0.1 \mathrm{~d}^{-1}$ and midpoints of $1.3 \pm 0.2$ and $4.5 \pm 0.2 \mathrm{~d}$ for basal and apical cells, respectively ( $r^{2}$ values were 0.95 and 0.99 for basal and apical cells). $\boldsymbol{F}$, The slow adaptation time constant is plotted against days in culture, again demonstrating a temporal delay between apical and basal development. Here, the data were fit with sigmoidal functions with baseline values, representing the mature response, that were not statistically different at $2.4 \pm 0.5$ and $2.6 \pm 0.8 \mathrm{~ms}$. The slopes were not different with values of $0.8 \pm 0.8$ and $1.1 \pm$ $0.5 \mathrm{~d}^{-1}$, whereas the midpoints were different with values of $4 \pm 1$ and $8 \pm 1 \mathrm{~d}$ for basal and apical cells, respectively ( $r^{2}$ were 0.76 and 0.95 for basal and apical fits).

uration was delayed by approximately $3 \mathrm{~d}$ compared with the basal OHCs. The shift in half-activation (Fig. 7C) did not correlate with a change in sensitivity (Fig. $7 B$ ) or with the magnitude of the MET current after P2 (Fig. 7D). When considering mechanisms of maturation, a change in slope is critical because a change would be expected if channels became responsive at different 

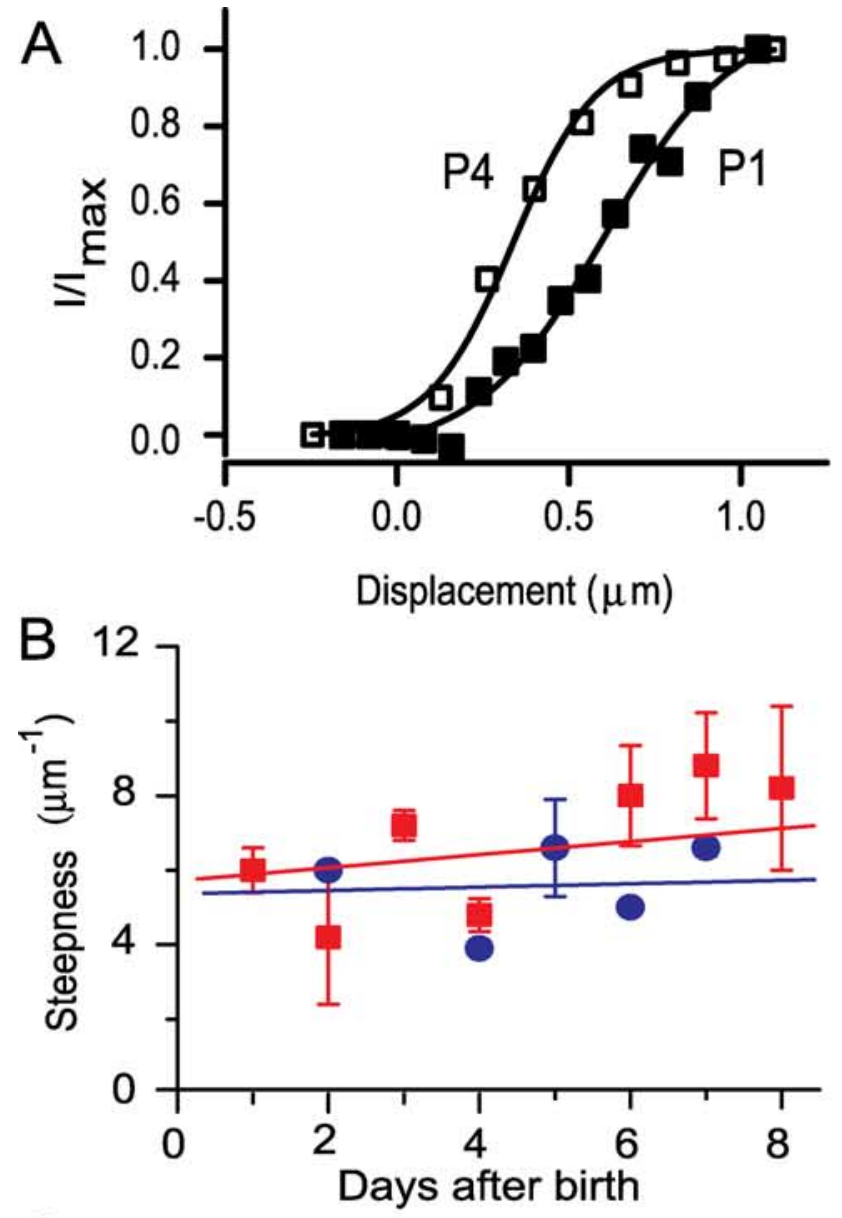

है
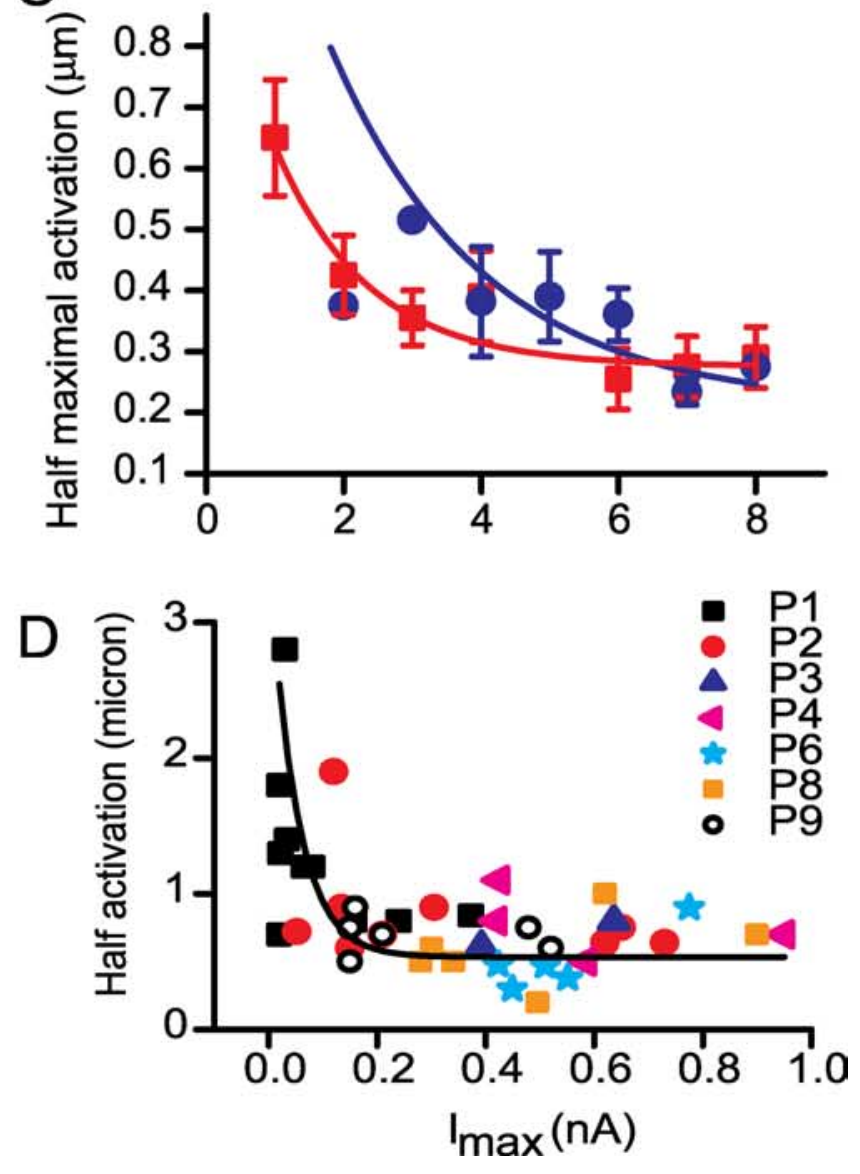

locations along the stereocilium (as a result of the change in stimulus amplitude along the height of the hair bundle). No change in slope was observed, suggesting that channels became responsive at a common location along the stereocilium. The time course of the shift in half-activation was fit with a singleexponential decay with time constants of $1.3 \pm 0.6$ and $2 \pm 1 \mathrm{~d}$ for basal and apical cells, respectively, with midpoints in the curves between apical and basal cells shifted in time by $3 \mathrm{~d}$.

A simple hypothesis regarding the shifting activation plot is that the initial right-shifted curve is in part a consequence of the hair bundle initially being mechanically passive and that as more MET channels become functional, the hair bundle mechanics become dictated by the channel mechanics (Marquis and Hudspeth, 1997). Given that there are one or two channels per stereocilium, the larger the MET current, the more functional stereocilia (those with working channels) per hair bundle. The shift in current-displacement may indicate the transition from a hair bundle whose mechanics are regulated by the passive bundle properties to one that is regulated by the active mechanics. This hypothesis predicts a relationship between the amplitude of the MET current and the position of the activation curve (i.e., resting probability of opening or half-activation). Figure $7 D$ defines this relationship and suggests that initially a strong correlation between current amplitude and half-activation exists (before P2) but that this relationship becomes weak after P2. The strongest correlation between half-activation and current amplitude occurs during the steepest portions of both the pruning process (Fig. 4) and the increased MET current (Fig. 5), lending credence to the hypothesis that the shift in activation is at least in part a function of the addition of functional stereocilia.

Myosin Ic may be a critical component of the adaptation machinery. It has been localized to hair bundles, and modifications that alter the ATP-binding site interfere with both the slow and fast components of adaptation (Holt et al., 2002; Stauffer et al., 2005). Immunolocalization of myosin Ic along the stereocilium during maturation revealed temporal and spatial gradients similar to those observed for the morphological and electrophysiological changes (Fig. 8). Measurements were made in both the acute and cultured preparations, where again no differences were observed. Basal hair bundle labeling preceded apical. Plotting the relative fluorescence intensities as measured from confocal images (Fig. 9A) against days after birth shows a distribution that can be fit with a sigmoidal function with a slope of $1.9 \pm 0.2$ and $1.7 \pm 0.5 \mathrm{~d}^{-1}$ and midpoints of $7.0 \pm 0.2$ and $9.8 \pm 0.5 \mathrm{~d}$ for basal and apical cells, respectively. Labeling followed a time course similar but broader than that of the maturation of adaptation (Fig. 7). To investigate the relationship between adaptation development and myosin Ic labeling, the fluorescence intensity for myosin Ic was plotted against the fast adaptation time constant (Fig. 9B). The plot demonstrates that the time constant matures

Figure 7. A, Examples of normalized current-displacement $(1-x)$ plots for basal cells recorded at P1 ( $I_{\max }$ was $\left.158 \mathrm{pA}\right)$ and $\mathrm{P} 4\left(I_{\max }\right.$ was $\left.595 \mathrm{pA}\right)$, demonstrating a leftward shift during maturation. $\boldsymbol{B}, C$, Data were fit with a single Boltzmann function to obtain information regarding the slope $(\boldsymbol{B})$ and half-activation properties $(\boldsymbol{C})$, both plotted against days after birth. № change was seen in the steepness, as demonstrated by the linear fits with slopes not different from 0 . The displacement to achieve half-activation shifts leftward over a time course that is similar to the maturation of the MET current response. Data fit with the equation for an exponential had a rate of change of $1.3 \pm 0.6$ and $2.1 \pm 1.1 \mathrm{~d}$ for basal $\left(r^{2}=0.91\right)$ and apical $\left(r^{2}=\right.$ 0.68). $\boldsymbol{D}$, Correlation between the half-activation displacement and the maximal transducer current. The relationship demonstrates that during the development state, there is a direct relationship that is lost in basal hair cells after $\mathrm{P2}$. The solid line is an exponential with a rate of change of $50 \pm 5 \mathrm{pA}^{-1}\left(r^{2}=0.9\right)$. 
for basal cells with the expression of 20\% of the final myosin Ic labeling, whereas the apical cells have $\sim 30 \%$ of the myosin Ic (Fig. 9B). Exponential fits to these data gave rates of change of $0.069 \pm 0.006 \mathrm{~ms}$ and $0.036 \pm 0.03 \mathrm{~ms}$ for apical $\left(r^{2}=0.99\right)$ and basal $\left(r^{2}=0.96\right)$ cells, respectively. If the adaptation rate were simply a function of myosin concentration, then a relationship would be expected in which apical and basal cells overlapped but faster basal cells had more myosin; this was not observed. However, this relationship may be masked by the overabundance of myosin Ic present compared with what would be required for adaptation, perhaps indicating multiple functions for myosin Ic.

A more direct association between myosin Ic and slow adaptation has been suggested (Holt et al., 2002). A similar plot of slow adaptation time constant against relative myosin Ic level again reveals a relationship that is different for basal and apical cells (Fig. 9C). Here, too, exponential functions were fit to the data and revealed rates of change that were not statistically significant $(0.17 \pm 0.13 \mathrm{~ms}$ compared with $0.17 \pm 0.03 \mathrm{~ms}$ for basal and apical cells, respectively).

A hallmark of mechanotransduction is directional sensitivity, in which the hair bundle responds best to a stimulus applied in a specific direction: toward the tallest row of stereocilia (Shotwell et al., 1981). Whether directional sensitivity develops as the hair bundle matures or is present at the onset of MET was addressed by stimulating immature hair bundles in directions either toward the shortest rows or orthogonal to the axis of sensitivity. Stimulating the bundle from behind or from the side in the adult hair bundle elicited only "off" responses. However, at $\mathrm{P} 3$ a variety of responses were observed, including those in Figure 10. In three P3 cells, negative stimulation evoked MET currents, which appeared similar to cells stimulated in positive directions (Fig. $10 \mathrm{~B}$ ), suggesting a lack of directional sensitivity. No MET currents were detectable from these cells at their resting hair bundle position. In two other cells, "off" responses were observed until large stimulation were used, and then currents were evoked as if the bundle were being stimulated positively. These larger responses were mixed in nature, having channels opening during the stimulation, but also having large "off" responses that appeared as tail current. The responses were elicited with the probe positioned either at the side of the hair bundle or directly at the back of the hair bundle (Fig. 10A). The hair bundle was imaged during stimulation, and there was no indication of bundle splaying that might result in a false positive. Interestingly, these results were not observed in more mature bundles.

\section{Discussion}

The onset of mechanosensitivity shows a temporal gradient with basal hair cells becoming responsive at P0 and apical cells at P3 (Fig. 5). This gradient was maintained in all properties related to MET and adaptation. The morphological development of the hair bundle and the localization of myosin Ic and IIIa showed similar spatial and temporal distributions (Fig. 11A). That base precedes apex mimics that observed in vivo for several key elements related to hair cell development (Fig. 11A), including exiting the cell cycle (Lee et al., 2006), onset of differentiation (Lee et al., 2006), and appearance of the hair bundle and myosins VII (Chen and Segil, 1999; Lee et al., 2006) and XVa (Rzadzinska et al., 2004). This temporal consistency suggests that hair cells are programmed to develop mechanosensitive hair bundles before birth.

Organotypic cultures develop normal MET properties expressing both temporal and spatial gradients during maturation and in their final response characteristics. Data suggest that developmental signals establishing tonotopic differences are either in place before birth or are locally regulated by supporting cells, but are not influenced significantly by external factors such as innervation, endolymph, normal mechanical stimulation, or an intact organ of Corti. There were hair bundles with unusual morphological shapes in culture. In particular, a loss of planar cell polarity in which hair bundles were oriented up to 90 degrees from their expected positions was frequently observed (Fig. 1), suggesting susceptibility of individual hair cells to local in vitro conditions.

MET matures over several days with activation and adaptation kinetics becoming faster, current amplitudes increasing, and current-displacement functions shifting leftward. In contrast, in vestibular hair cells (Geleoc and Holt, 2003) the earliest measurements were identical to mature responses. The discrepancy may reflect intrinsic differences between systems or a rapid matura- 
A

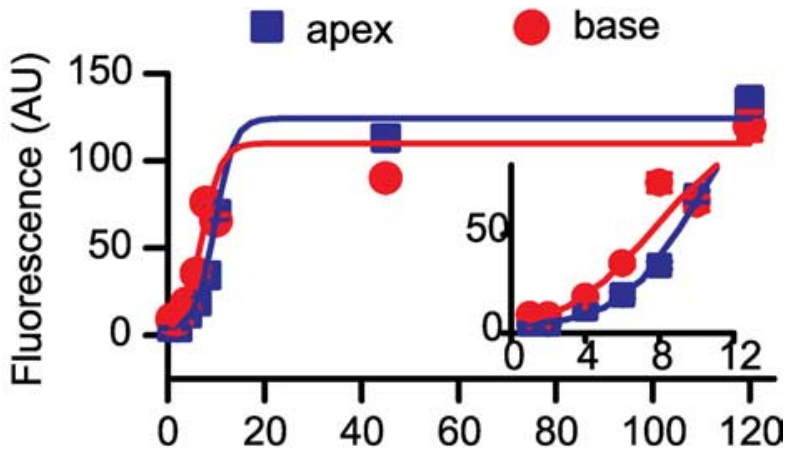

B

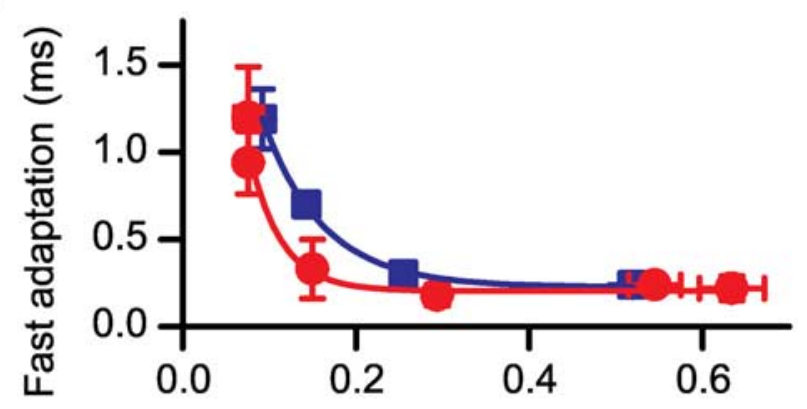

Myosin/myosin

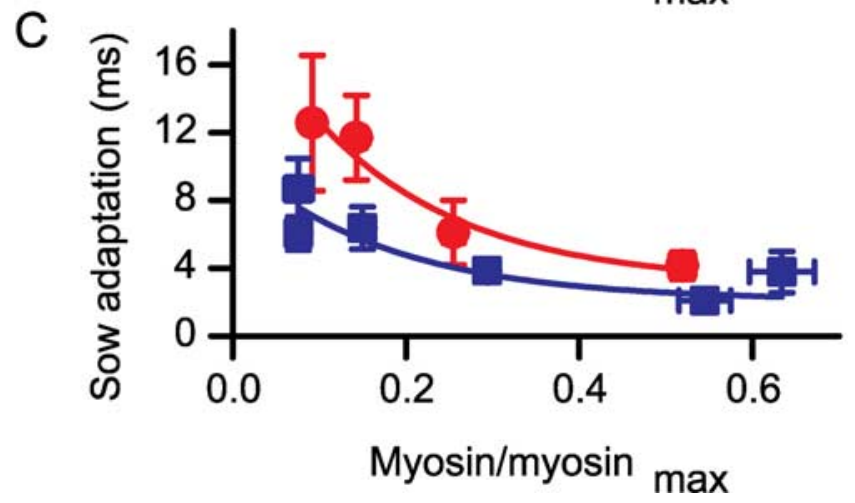

Figure 9. A, Data from Figure 8 were quantified by measuring fluorescence intensity (minus background) for bundles at each location and plotted against age. Data were fit with sigmoidal functions with slope values of $1.7 \pm 0.5$ and $1.9 \pm 0.2(\mathrm{AU} / \mathrm{d})$ and midpoints of $9.8 \pm 0.5$ and $7.0 \pm 0.2 \mathrm{~d}$ for apical $\left(r^{2}=0.99\right)$ and basal cells $\left(r^{2}=0.97\right)$, respectively. $A$, Inset, The initial $12 \mathrm{~d}$ for the plot in $A$ to show the separation between apex and base. The $n$ for each point is given near the data point. $\boldsymbol{B}$, The normalized myosin I intensity is plotted against the fast adaptation time constant for apical (blue) and basal cells (red). Single-exponential fits were used in which the rate of change for apical cells was measured as $0.07 \pm 0.01 \mathrm{~ms}$ compared with $0.04 \pm 0.03$ $\mathrm{ms}$ for basal cells ( $r^{2}$ values for fits were 0.99 and 0.96 for apical and basal cells, respectively). $C$, Similar plots were made for the slow time constant of adaptation resulting in rates of change of $0.17 \pm 0.13$ and $0.17 \pm 0.03 \mathrm{~ms}$ for apical $\left(r^{2}=0.69\right)$ and basal cells $\left(r^{2}=0.95\right)$, respectively.

tion process in which early MET responses were undetected in vestibular cells. The latter is plausible because an order of magnitude larger stimulus was required to saturate immature auditory hair cells ( $\sim 2 \mu \mathrm{m}$ compared with $0.2 \mu \mathrm{m}$ for mature) that would scale to $5-10 \mu \mathrm{m}$ for vestibular hair bundles, stimuli more likely to damage hair bundles than elicit currents.

Several factors lead to a broadening of the developmental time courses presented, including recording periods lasting typically $12 \mathrm{~h}$. Given the tonotopic gradient in development, the region over which we collected data represents variance of $\sim 12 \mathrm{~h}$ as well so that each data point represents $\pm 1 \mathrm{~d}$. The effect of these variations is depicted in the acquisition of mechanosensitivity in apical cells, in which cells went from little or no response on P3 to larger currents on $\mathrm{P} 4$, reminiscent of the "all-or-none" response with respect to current amplitude but not for adaptation properties.

Data presented are similar to those described in avian auditory hair cells (Si et al., 2003) but for shift in the activation curve. In contrast to data presented here, the activation curve shifted from left to right in avian basilar papilla, indicating a large probability of opening that decreased during maturation. There is no clear explanation for this disparity. Perhaps species differences related to variations in bundle morphology or perhaps the stimulation method, fluid jet versus stiff fiber, contributed to the difference. If hair bundles are initially more compliant, then the fluid jet might overstimulate the bundle when being positioned (personnel communication, Ebenezer Yamoah). A leftward shift in activation was observed in the recovery of MET in hair bundles that had been treated with BAPTA to destroy interciliary linkages (Zhao et al., 1996).

That MET currents do not immediately present as mature responses does not negate the possibility that MET machinery assembles at the hair bundle base and migrates to the tops of stereocilia, because MET properties are predicted to vary if mechanosensitivity begins before the channels reaching the stereocilium tops. The lack of slope change in the current-displacement plot, predicted by channels being mechanically active as they migrate up the stereocilia, the promiscuity of directional sensitivity in the immature response, and the myosin Ic immunoreactivity lagging the onset of mechanosensitivity by nearly $2 \mathrm{~d}$, implies independent migration of components.

Independent migration of MET components can account for all present data as being a reflection of when proteins arrive in sufficient concentrations to affect response properties. Tracking the midpoints of the measured MET properties supports this simple notion. Mechanosensitivity in basal cells has a midpoint of P0, current amplitude of P2.4, radial links and stereocilium pruning of P2.5, fast adaptation time constant of P3, the slow time constant of P5, and myosin Ic labeling of P7. Current amplitude increases as channels arrive at the top, whereas activation kinetics get faster as membrane tension increases, likely by the increased tensioning of the tip link. Directional sensitivity occurs as radial links are pruned, rendering stereocilia sensitive to stimuli applied in one direction. Thus, a "tensioning" hypothesis, consistent with existing data, is proposed in which maturation, indicated by an increased sensitivity and faster kinetics, occurs as tension in the tip link increases (Fig. 11).

Directional sensitivity in immature responses is somewhat promiscuous, suggesting that mechanosensitivity may be generated by channels sensing stimulus from radial links that cannot be definitively identified as tip links by scanning electron microscopy. Studies using hamster suggested that tip links appear at P4, well after the onset of mechanosensitivity (Kaltenbach et al., 1994). However, present data could not specifically distinguish between radial links and tip links near the tips of stereocilia. Directional promiscuity can be reconciled in a system in which the channel is not tethered but rather responding to membrane stretch. In a nontethered scenario, directional sensitivity occurs simply by pruning radial links, allowing membrane stretch to occur only along the axis of sensitivity. Recent data from a myosin XV knock-out mouse indirectly supports the model in demonstrating that relatively normal transduction can be obtained where tip links cannot be clearly distinguished and the bundles are in an immature state (Stepanyan et al., 2006). It is interesting 

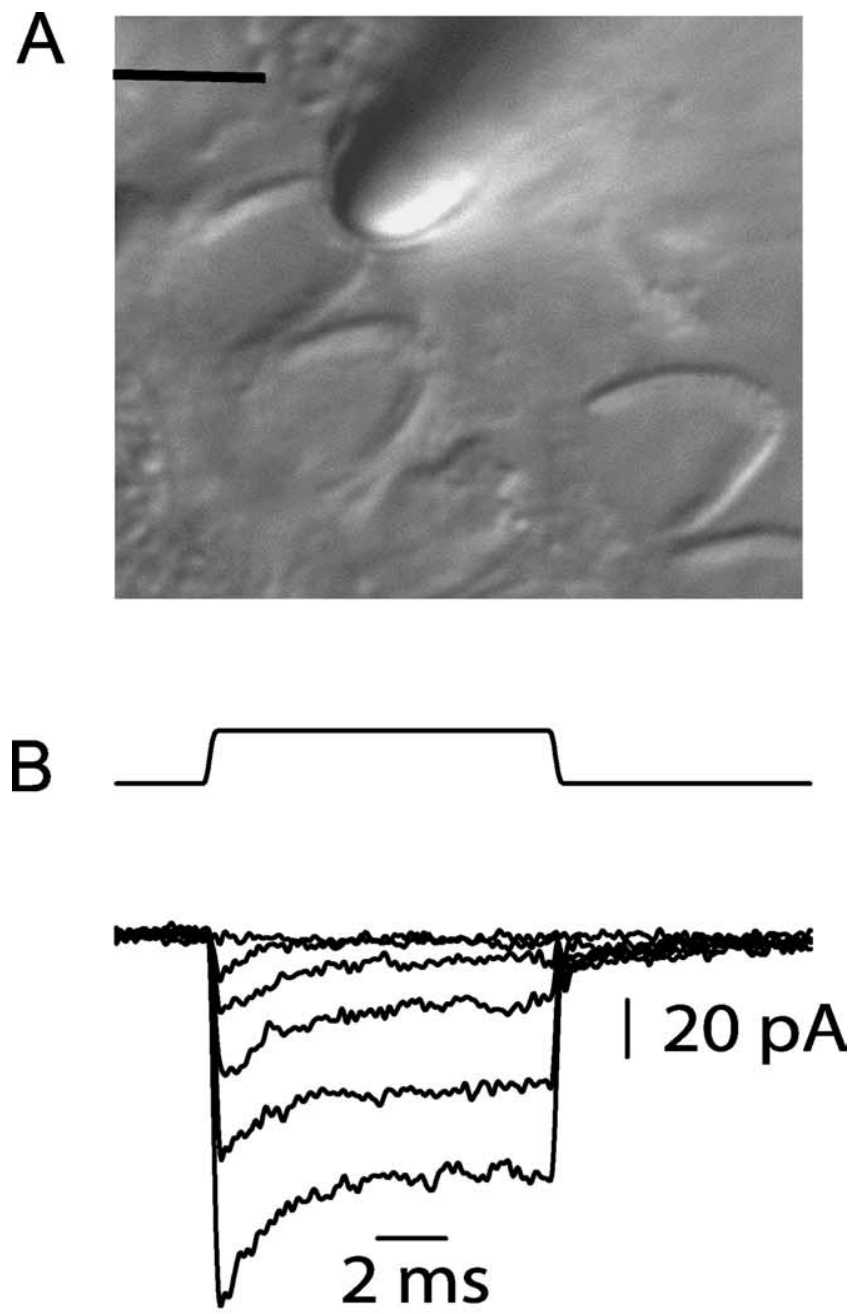

C

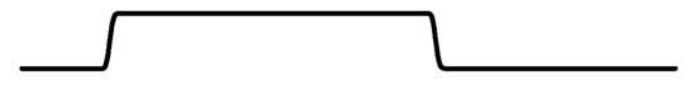

a

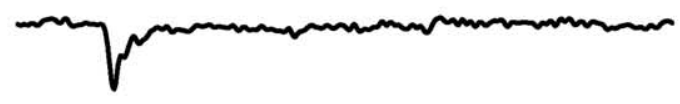

b

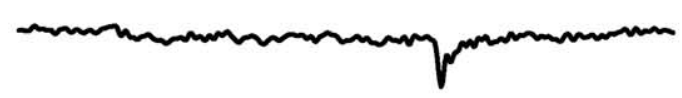

C

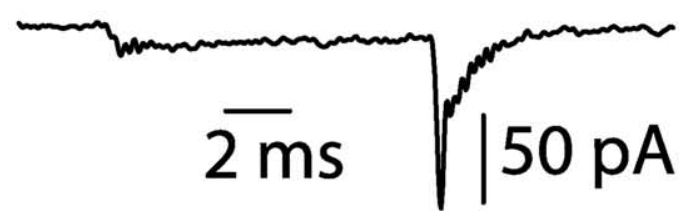

Figure 10. Immature bundles show a lack of directional sensitivity. $A$, Example of a probe positioned at the back end of an $\mathrm{OHC}$ hair bundle. Scale bar, $10 \mu \mathrm{m}$. Positions of directly behind the center of the hair bundle or behind one side of the hair bundle were used with no apparent difference in response properties. $\boldsymbol{B}, \mathrm{A}$ response from a $\mathrm{P} 3$ basal hair cell stimulated (shown above current) with the probe behind the bundle so that stimuli that would normally close channels opened channels. There was no current on at rest in these cells. Similar responses were obtained in three cells. C, A mixed response, also obtained with the probe behind the hair bundle. Stimuli toward the kinocilium opened channels $(\boldsymbol{a})$, whereas stimuli away from the kinocilium largely produced off

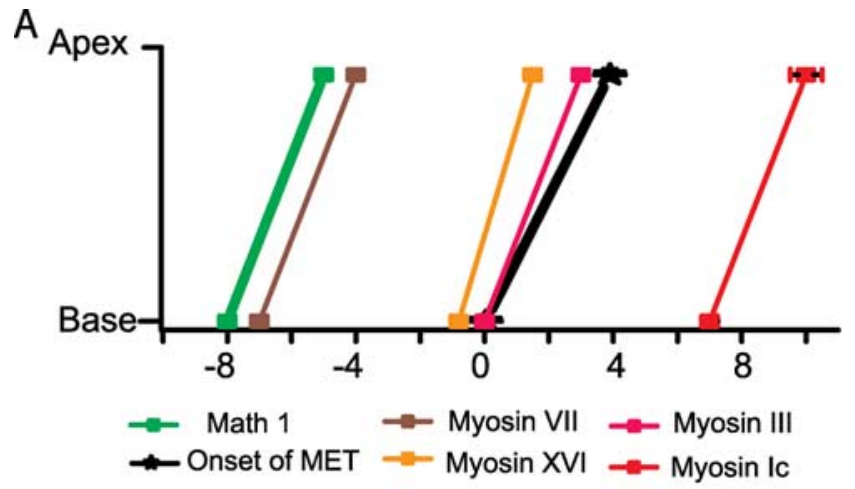

B
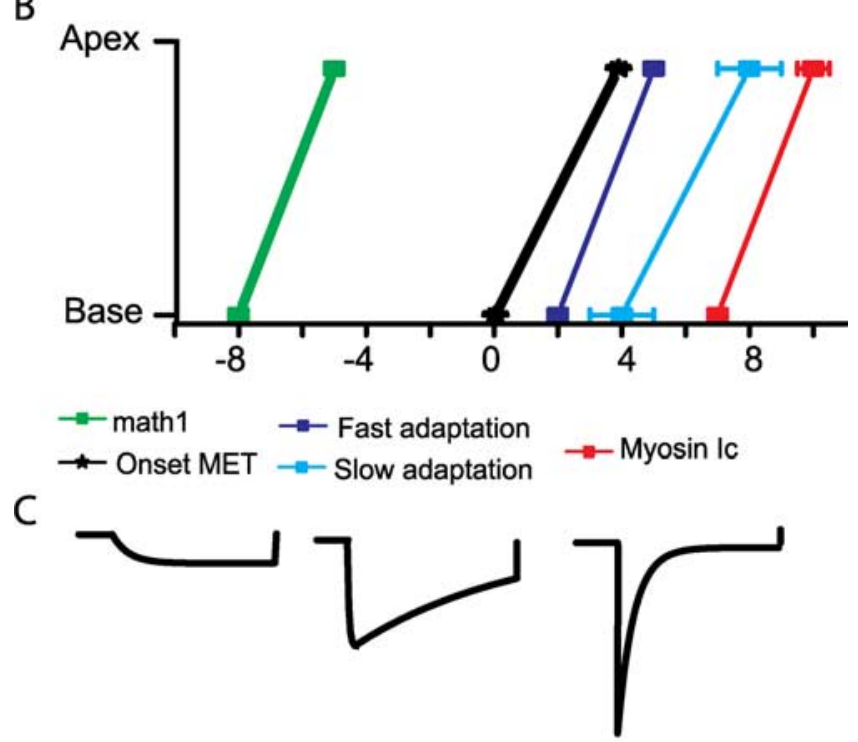

D
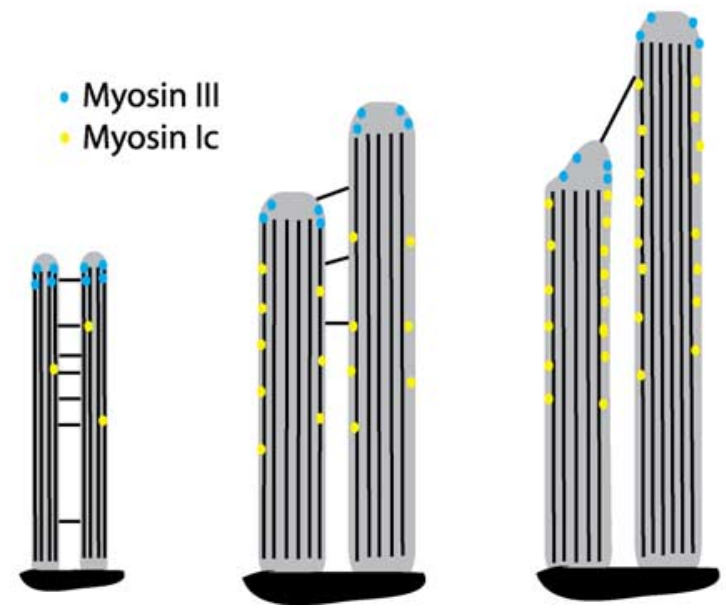

Figure 11. Summary of stepwise maturation time course of the hair bundle and mechanosensitivity in relation to cochlear development. $A$, Time line of key events from exiting the cell cycle, to expression of transcription factor math1, to maturation of adaptation. $\boldsymbol{B}$, Stages of development depicting stereocilium maturation, thickening, elongation, pruning of interciliary links, the appearance of myosin lc, the onset of mechanosensitivity, and the appearance of directional sensitivity. $C$, Schematized MET responses. $\boldsymbol{D}$, Top-down view of stereocilia depicting the pruning of interciliary linkages. Blue represents myosin Illa, and yellow represents myosin Ic.

$\leftarrow$

responses as indicated by the overshoot in the tail current $(\boldsymbol{b})$. However, larger negative stimuli were capable of producing a mixed response that both opened and closed channels (c). This response shows channels opening when the bundle was pushed in the off direction, but the return to baseline elicited a current implicating channel closure, i.e., tail current. 
to note that the tip links and the transient or developmental radial links both have cadherin 23 and protocadherin 15 (Kazmierczak et al., 2007) and therefore may be related structures. Perhaps radial links are precursors of tip links that can engage the MET channels and exert effective tension in the membrane before reaching their position at the tips of stereocilia.

Myosin Ic has been implicated as underlying both fast and slow adaptation (Holt et al., 2002; Stauffer et al., 2005), although its role in mammalian cochlea adaptation remains to be determined. Fast adaptation is also postulated as an intrinsic channel property (Crawford et al., 1991; Cheung and Corey, 2005). No data to date, including those presented here, can delineate between mechanisms of fast and slow adaptation or can define the interplay between mechanisms. The lack of adaptation in early recordings does not discount the channel mechanism because (1) slow activation kinetics can mask the temporal adaptation response (Wu et al., 1999), (2) small current amplitudes slow adaptation kinetics (Ricci et al., 1998; Kennedy et al., 2003), and (3) loss of myosin Ic would reduce fast adaptation whether causally involved in the process or not, as would any component linking the MET channel to the stimulus. Thus whether the change in fast adaptation is attributable to the direct maturation of the fast process or is secondary to hair bundle maturation and the slow process that indirectly increases activation kinetics unmasking the fast adaptation process remains to be explored. Adaptation matures days before myosin Ic levels have maximized, suggesting that myosin Ic has other functions. This is consistent with the myosin Ic distribution, which differs in rodents versus frog or bird by being localized along the entire stereocilium length (Garcia et al., 1998; Steyger et al., 1998; Schneider et al., 2006).

Slow adaptation develops more gradually and later in time than fast adaptation. Slow adaptation rates are faster than reported in any other hair cell system by an order of magnitude or more and so may not represent the conventional slow process. An even slower form of adaptation may be present but not observed because of shorter duration stimulations. The specific role of myosin Ic in these processes remains to be explored.

Myosin IIIa correlates with mechanosensitivity onset, perhaps hinting for a role in delivering key proteins to the site of MET. In Drosophila, myosin IIIa is important for assembly and organization of transduction machinery of photoreceptors (Meyer et al., 2006). Loss of myosin IIIa leads to progressive hearing loss in humans (Walsh et al., 2002). Myosin IIIa has slow kinetics and relatively high affinity for actin, supporting a role as an actin cross-linker and a transporter (Kambara et al., 2006; Dose et al., 2007), and it shares structural features with myosin $X$ and myosin $\mathrm{XVa}$, which are implicated in cargo transport to the tip of actin protrusions (Berg and Cheney, 2002; Belyantseva et al., 2005). The correlation between myosin IIIa localization and the increase in MET current is consistent with this type of transport role in the ear.

Present data delineate the time course of onset and maturation of mechanotransduction in rat OHCs. A hypothesis is put forth suggesting that the required proteins arrive independently at the site of MET and that maturation is a reflection of an increase in membrane tension promoting rapid and accurate transfer of hair bundle deflection to force at the MET channel.

\section{References}

Belyantseva IA, Boger ET, Naz S, Frolenkov GI, Sellers JR, Ahmed ZM, Griffith AJ, Friedman TB (2005) Myosin-XVa is required for tip localization of whirlin and differential elongation of hair-cell stereocilia. Nat Cell Biol 7:148-156.
Berg JS, Cheney RE (2002) Myosin-X is an unconventional myosin that undergoes intrafilopodial motility. Nat Cell Biol 4:246-250.

Chen P, Segil N (1999) p27(Kip1) links cell proliferation to morphogenesis in the developing organ of Corti. Development 126:1581-1590.

Cheung EL, Corey DP (2005) Ca2 + changes the force sensitivity of the haircell transduction channel. Biophys J 90:124-139.

Corey DP, Hudspeth AJ (1979) Response latency of vertebrate hair cells. Biophys J 26:499-506.

Crawford AC, Evans MG, Fettiplace R (1991) The actions of calcium on the mechano-electrical transducer current of turtle hair cells. J Physiol (Lond) 434:369-398.

Dose AC, Ananthanarayanan S, Moore JE, Burnside B, Yengo CM (2007) Kinetic mechanism of human myosin IIIA. J Biol Chem 282:216-231.

Dumont RA, Zhao YD, Holt JR, Bahler M, Gillespie PG (2002) Myosin-I isozymes in neonatal rodent auditory and vestibular epithelia. J Assoc Res Otolaryngol 3:375-389.

Eatock RA, Corey DP, Hudspeth AJ (1987) Adaptation of mechanoelectrical transduction in hair cells of the bullfrog's sacculus. J Neurosci 7:2821-2836.

Friedman PL, Ellisman MH (1981) Enhanced visualization of peripheral nerve and sensory receptors in the scanning electron microscope using cryofracture and osmium-thiocarbohydrazide-osmium impregnation. J Neurocytol 10:111-131.

Garcia JA, Yee AG, Gillespie PG, Corey DP (1998) Localization of myosinIbeta near both ends of tip-links in frog saccular hair cells. J Neurosci 18:8637-8647.

Geleoc GS, Holt JR (2003) Developmental acquisition of sensory transduction in hair cells of the mouse inner ear. Nat Neurosci 6:1019-1020.

Gillespie PG, Cyr JL (2004) Myosin-1c, the hair cell's adaptation motor. Annu Rev Physiol 66:521-545.

He DZ, Jia S, Dallos P (2004) Mechanoelectrical transduction of adult outer hair cells studied in a gerbil hemicochlea. Nature 429:766-770.

Holt JR, Gillespie SK, Provance DW, Shah K, Shokat KM, Corey DP, Mercer JA, Gillespie PG (2002) A chemical-genetic strategy implicates myosin-1c in adaptation by hair cells. Cell 108:371-381.

Hudspeth AJ (1982) Extracellular current flow and the site of transduction by vertebrate hair cells. J Neurosci 2:1-10.

Hudspeth AJ (1989a) How the ear's works work. Nature 341:397-404.

Hudspeth AJ (1989b) Mechanoelectrical transduction by hair cells of the bullfrog's sacculus. Prog Brain Res 80:129-135.

Hudspeth AJ, Gillespie PG (1994) Pulling springs to tune transduction: adaptation by hair cells. Neuron 12:1-9.

Kaltenbach JA, Falzarano PR, Simpson TH (1994) Postnatal development of the hamster cochlea. II. Growth and differentiation of stereocilia bundles. J Comp Neurol 350:187-198.

Kambara T, Komaba S, Ikebe M (2006) Human myosin III is a motor having an extremely high affinity for actin. J Biol Chem 281:37291-37301.

Kazmierczak P, Sakaguchi H, Tokita J, Wilson-Kubalek EM, Milligan RA, Muller U, Kachar B (2007) Cadherin 23 and protocadherin 15 interact to form tip-link filaments in sensory hair cells. Nature 449:87-91.

Kennedy HJ, Evans MG, Crawford AC, Fettiplace R (2003) Fast adaptation of mechanoelectrical transducer channels in mammalian cochlear hair cells. Nat Neurosci 6:832-836.

Lee YS, Liu F, Segil N (2006) A morphogenetic wave of p27Kip1 transcription directs cell cycle exit during organ of Corti development. Development 133:2817-2826.

Marquis RE, Hudspeth AJ (1997) Effects of extracellular Ca2 + concentration on hair-bundle stiffness and gating-spring integrity in hair cells. Proc Natl Acad Sci USA 94:11923-11928.

Meyer NE, Joel-Almagor T, Frechter S, Minke B, Huber A (2006) Subcellular translocation of the eGFP-tagged TRPL channel in Drosophila photoreceptors requires activation of the phototransduction cascade. J Cell Sci 119:2592-2603.

Prost J, Barbetta C, Joanny JF (2007) Dynamical control of the shape and size of stereocilia and microvilli. Biophys J 93:1124-1133.

Ricci A (2003) Active hair bundle movements and the cochlear amplifier. J Am Acad Audiol 14:325-338.

Ricci AJ, Wu YC, Fettiplace R (1998) The endogenous calcium buffer and the time course of transducer adaptation in auditory hair cells. J Neurosci 18:8261-8277.

Ricci AJ, Kennedy HJ, Crawford AC, Fettiplace R (2005) The transduction channel filter in auditory hair cells. J Neurosci 25:7831-7839. 
Rzadzinska AK, Schneider ME, Davies C, Riordan GP, Kachar B (2004) An actin molecular treadmill and myosins maintain stereocilia functional architecture and self-renewal. J Cell Biol 164:887-897.

Schneider ME, Dose AC, Salles FT, Chang W, Erickson FL, Burnside B, Kachar B (2006) A new compartment at stereocilia tips defined by spatial and temporal patterns of myosin IIIa expression. J Neurosci 26:10243-10252.

Shotwell SL, Jacobs R, Hudspeth AJ (1981) Directional sensitivity of individual vertebrate hair cells to controlled deflection of their hair bundles. Ann NY Acad Sci 374:1-10.

Si F, Brodie H, Gillespie PG, Vazquez AE, Yamoah EN (2003) Developmental assembly of transduction apparatus in chick basilar papilla. J Neurosci 23:10815-10826.

Stauffer EA, Scarborough JD, Hirono M, Miller ED, Shah K, Mercer JA, Holt JR, Gillespie PG (2005) Fast adaptation in vestibular hair cells requires Myosin-1c activity. Neuron 47:541-553.
Stepanyan R, Belyantseva IA, Griffith AJ, Friedman TB, Frolenkov GI (2006) Auditory mechanotransduction in the absence of functional myosinXVa. J Physiol (Lond) 576:801-808.

Steyger PS, Gillespie PG, Baird RA (1998) Myosin Ibeta is located at tip-link anchors in vestibular hair bundles. J Neurosci 18:4603-4615.

Walsh T, Walsh V, Vreugde S, Hertzano R, Shahin H, Haika S, Lee MK, Kanaan M, King MC, Avraham KB (2002) From flies' eyes to our ears: mutations in a human class III myosin cause progressive nonsyndromic hearing loss DFNB30. Proc Natl Acad Sci USA 99:7518-7523.

Wu Y-C, Ricci AJ, Fettiplace R (1999) Two components of transducer adaptation in auditory hair cells. J Neurophysiol 82:2171-2181.

Zhao Y, Yamoah EN, Gillespie PG (1996) Regeneration of broken tip-links and restoration of mechanical transduction in hair cells. Proc Natl Acad Sci USA 93:15469-15474.

Zine A, Romand R (1996) Development of the auditory receptors of the rat: a SEM study. Brain Res 721:49-58. 